\title{
2. Der Charakter der Quellen und ihre Bedeutung
}

2.1. Wie schon früher erwähnt, ist gerade um das Problem des Ūsin̨š das erste Mal in der Erforschung der Religion der Letten die Frage nach den Quellen, nach deren unterschiedlichem Charakter und deren Bedeutung für die Bestimmung des Wesens des Ūsiṇš ernsthaft diskutiert worden. Wenn hier ein Überblick über die Quellen, die in dieser Arbeit ausgewertet wurden, geboten wird, so ist deren kritischer Bewertung besondere Aufmerksamkeit zu widmen.

2.1.1. Wenn über Zeugnisse historischer Urkunden geredet wird, muß gesagt werden, daß im Zusammenhang mit Ūsinš eine besondere Lage besteht. Es ist dies einer der seltenen Fälle in der Erforschung der lettischen Religion, wo in einem glaubhaften historischen Dokument Nachrichten über Üsiņš enthalten sind. Diese Nachrichten reichen bis in das Jahr 1606 zurück, als Stribiņš sie niederschrieb. Wer war dieser Stribiñ̌̌? Auch in diesem Falle hat man es mit einer besonderen Erscheinung zu tun. Als nach der Eroberung eines Teils Lettlands durch den polnischen König Stephan Batory der Jesuitenorden dort seine Arbeit aufnahm, wurden in ganz seltenen Fällen auch Letten in diesen Orden aufgenommen ${ }^{1}$. Das ist verständlich, denn der Orden mußte im Kampf gegen die Reformation möglichst auch die Unterstützung der einheimischen Bevölkerung anstreben. Da waren Einheimische mit Kenntnissen der lettischen Sprache eine große Hilfe. So wurde auch Stribiņš zur Missionsarbeit im fernen Grenzgebiet Lettlands abgeordnet. In einem Bericht an das Jesuitenkollegium in Riga über seine Tätigkeit und seine Beobachtungen bringt er unter anderem auch Angaben über Üsinšs. In seiner Schrift ist zu lesen: Deo Equorum, quem vocant Dewing Vschinge offerunt singuli 2 solidos et duas panes et frustrum pinguedinis, quam im ignem conjiciunt ${ }^{2}$. Diese Worte enthalten eine umfassende Beschreibung, die ein ziemlich genaues und vollständiges Bild

1 Über Stribin̄̌s hat Kučinskis, $28 \mathrm{~s}$, geschrieben.

2 VA. Ms I, 19. Diesen Text hat Kleijntjens aus dem Originalmanuskript veröffentlicht (ef. Fontes 2, 105). Schon früher hatte Lohmeyer, 390 s, diesen Text nach einer Abschrift veröffentlicht, doch er schreibt Uschinge. 
der religiösen Tradition, die in jener Gegend lebendig waren, darstellt. Darin sind auch die Namen anderer Götter, die diesen gebrachten Opfer und die entsprechenden Anbetungsweisen genannt.

Das Mitglied des Rigaschen Jesuitenkollegiums Tolgsdorff hat die Meldung des Stribiņš bei der Abfassung des Jahresberichts für die Personalführung der Jesuiten benutzt. Er selbst hat die Verhältnisse am Ort nicht kennengelernt, die Stribiņš beschreibt. Er hat die Worte des Stribiņš nur ein wenig umformuliert: Equorum deum nominant Usching [...]1. Tolgsdorffs Aufgabe war es, die Zusammenfassung der Berichte über die Jahresarbeit an die Ordensleitung zu übersenden. Dort wurde sie offensichtlich nochmals umformuliert: Equorum Deum vocantes Vseling, und so ist es dann im Jahresüberblick des Jesuitenordens abgedruckt².

In einem Protokoll von 1613 ist noch einmal eine Meldung des Stribiṇš in anderem Zusammenhang zu finden. Protokolliert war die Visitatio ecclesiarum facta anno 1613 a die Transfigurationis Domini usque ad $11^{\text {am }}$ Octobris per R.D. Archidiaconum Vendensem et $R^{m i}$ Episcopi Livoniae Vicarium ${ }^{3}$. Da Tolgsdorff der Protokollführer war, hat er die von ihm 1606 geschriebenen Worte wörtlich wiederholt. Dieses Protokoll ist mehrfach abgeschrieben worden und nach einer späteren Abschrift auch gedruckt worden ${ }^{4}$. Darum darf nur von einer Quelle gesprochen werden, nämlich von der Meldung des Stribiņš an das Rigasche Jesuitenkollegium von 1606.

Die Meldung des Stribiņš läßt dreierlei festhalten. Erstens des Gottes Name. Die graphische Form seiner Schreibung sieht so aus: Vschinge. Nach der damals eben erst in Entstehung begriffenen lettischen Schriftsprache schrieb man die Endung -iņš als ing. Das erklärt sich daraus, daß die ersten lettischen Schriften von Deutschen geschrieben worden sind und zwar unter dem Einfluß des Niederdeutschen. Diese hatten einfach phone-

1 Auch dieser Text ist im obenerwähnten Originalmanuskript enthalten. Er wurde in Fontes 2, $109 \mathrm{~s}$. veröffentlicht. Weiter sagt Mannhardt, 1936, 445, auch er habe diesen Text nach demselben Originalmanuskript veröffentlicht und schreibt: Equorum deum vocant Usching. Eine Abweichung besteht darin, daß Stribiṇš selbst vocant schreibt, Tolgsdorff aber nominant, Mannhardt aber wieder vocant.

2 Literæ 786. So ist es nochmals bei Kurtz, 183, abgedruckt, doch mit U geschreiben - Useling.

3 RA Livonica II, 643. Mannhardt, 1936, 450, spricht sich für die Ansicht aus, daß „die Handschrift des Schwedischen Reichsarchivs sogar Tolgsdorffs Urschrift sein [könnte], welche den Schweden bei ihrer Eroberung Wendens [Cēsis] oder Rigas in die Hände gefallen sein mag." (Näheres darüber bei Walde 43 ss und Biezais 1957, 26 ss).

4 Von der Stockholmer Handschrift hat Witte (über Leben und Arbeit desselben Recke 4, 548) eine Abschrift gemacht, von der in späteren Jahren mehrere Abschriften gemacht wurden, sowohl direkte, wie sekundäre (cf. Mannhardt 1936, 450 s): Protocoll 72; Hupel 538. 
tische Schwierigkeiten bei der Aussprache von -inš, und, wie es scheint, noch größere bei dessen schriftlicher Wiedergabe ${ }^{1}$.

Es ist bezeichnend, daß der germanisierte lettische Geistliche seinen lettischen Familiennamen Auniņš nicht nur Auning schreibt, sondern auch die folgende Erklärung dafür gibt, warum er anstelle der Endung -in̋̌s die Schreibung -ing verwendet: ,Wir haben uns entschlossen, denselben nach deutscher Orthographie 'UhBing' zu schreiben, weil diese Zeilen möglicherweise auch solchen Lesern in die Hände kommen könnten, die des Lettischen nicht mächtig sind. "2 Das entspricht voll den eben erwähnten Motiven und dabei noch 1881, 275 Jahre später. Auniñš erwähnen wir hier gerade deshalb, weil wir es hinfort mehrfach mit seinen Forschungen zu tun haben werden. Der Endung -ing ist im Wort $V$ schinge noch ein -e beigefügt. Das ist tatsächlich ein unnützer Buchstabe, und Ozols sagt, daß eine solche Hinzufügung eines unnützen Vokalzeichens, wie auch das Weglassen von Zeichen, wo sie an anderer Stelle erforderlich wären, einfach auf Unkenntnis der Sprache zurückzuführen sei. Darum fehlt in der Schreibweise von Tolgsdorff sowohl 1606 wie 1613 dieses -e ganz richtig. Bei der Schreibung des Namens in unserem Text ist noch anzumerken, daß nach der Gewohnheit der Schreibung des Lateinischen in der damaligen Zeit das $V$ statt des $U$ steht.

Die Transliterierung dieses Namens in die heutige lettische Sprache hat freilich auch hinfort ihre Schwierigkeiten. Erstlich ist aus der Schreibung des Stribinšs die phonetische Qualität des Lautes, den er mit -sch bezeichnet, nicht zu bestimmen. In alten lettischen Schriften bestehen hauptsächlich die größten Schwierigkeiten mit diesem Lautzeichen, weil es ebensogut den stimmhaften wie den stimmlosen Zischlaut bezeichnen kann. Im ersten Fall wäre es der Laut im französischen jardin, im zweiten der im deutschen schön. In der heutigen lettischen Schreibweise schreibt man im ersten Falle - ้̌-, im zweiten -š-3. Ebensowenig ist aus der Schreibweise des Stribiṇš zu ersehen, ob der erste Buchstabe im Wort lang oder kurz zu sprechen ist" Die zwei Unsicherheiten ermöglichen vier Transliterierungsmöglichkeiten:

1 So Ozols 1965, 76: „Niederdeutschen Menschen waren unsere (d.i. die lettischen) Laute $c, d z, \check{s}, \check{z}, \check{c}, d \check{z}$ völlig fremd und nicht auszusprechen. Wir wollen daher das Bestreben der Fremdlinge verstehen, die ungewohnten lettischen Laute auf bekannte zu reduzieren." So entstand auch -ing aus -inš. Cf. auch Zemzare, Daina 1961, 28 s.

2 Auniņš 1881, 7.

3 Näheres darüber bei Endzelins 1951, $27 \mathrm{~s}, \S 10$; Gramatika 1, 31 s, § 61-62. Über die Unbestimmtheit des Gebrauchs von $s$ und sch besonders Augstkalns 102 ss; cf. auch Ozols 1965, 77; Zemzare, Daina 1961, 16.

4 Ozols 1965, 75: ,Die exste Schriftsprache beruht auf niederdeutschen Verfahren: die Vokallänge wird nicht gekennzeichnet (einige Ansätze kann man spüren, aber es gibt kein System [...]." 


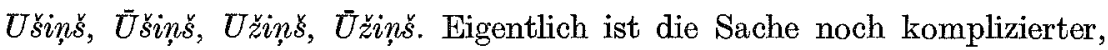
weil die damalige Schreibweise das -sch-auch zur Kennzeichnung des stimmhaften (deutsch, ,so") und des stimmlosen - $s$ - (französisch ,,ce") verwendet. Das bedeutet, daß der Name auch mit einem dieser beiden Laute gesprochen sein könnte, und dann natürlich auch mit langem oder kurzem -u-, also: Usiņš, Usiņš, Uziņš, Uziņš. Hierbei kann auch Tolgsdorffs spätere Schreibweise nicht helfen. Allein 1606 schreibt er den Anfangsbuchstaben U und ohne das unnütze -e-, nämlich Usching, 1613 aber wieder Vsching.

Die in den von der Zentralverwaltung des Jesuitenordens herausgegebenen Annuæ anzutreffende Schreibweise Useling ist ein Fehler, der auf falsches Abschreiben zurückzuführen ist.

2.1.2. In der Meldung des Stribiņ̌s ist das Wort Vschinge mit dem Wort Dewing zur Wortgruppe Dewing Vschinge zusammengesetzt. Deshalb muß man sich auch mit dem ersten Wort dieser Wortgruppe befassen. Es besteht keine Schwierigkeit, dieses Wort in die heutige Schreibweise -Dievinž- zu transliterieren. Auch in diesem Wort finden wir die Endung -ing anstelle der richtigen -inš. Keinerlei Schwierigkeiten verursacht auch der Vokal -eanstelle des richtigen Diphtongs -ie-. Denn auch das ist in alten lettischen Texten eine gewöhnliche Erscheinung, die sich aus den oben erwähnten Umständen erklärt ${ }^{1}$. Es ist noch anzumerken, daß man jetzt im Lettischen Gattungsnamen mit kleinem Anfangsbuchstaben schreibt, weswegen das auch hier zu erwarten wäre. Wenn nun aber Dewing mit großem Anfangsbuchstaben geschrieben ist, ist anzunehmen, daß dieses in Anlehnung an die Großschreibung der Substantiva im Deutschen geschehen ist. Weniger glaubhaft erscheint, daß solches geschah, weil es sich hier um die Bezeichnung einer Gottheit handelt, denn der Jesuit Stribiņ̌s wird doch wohl zwischen einem christlichen Gott und den heidnischen Gottheiten, von denen er hier spricht, unterschieden haben. So sind wir nach Überprüfung der zur Wortgruppe gehörenden Wörter zur richtigen Transliterierung gelangt: dievinš $\bar{U}$ sinšs, wobei wir freilich die Frage offen lassen nach der richtigen Schreibung des zweiten Wortes.

Welche ist denn nun dieses Ausdrucks semantische Bedeutung? Rein linguistisch ist sie ohne Schwierigkeit zu bestimmen. Stribinš spricht mit diesen Wörtern in wörtlicher Übersetzung vom „Göttchen Üsiņš“. Dabei ist jedoch anzumerken, daß die Wortform mit der Endung -inš formal linguistisch ein Deminutiv ist, die Form selbst aber kein hinreichender Grund zur Annahme, es wäre hier wirklich an die Verkleinerungsform des Wortes dievs gedacht. Im lettischen gibt es zahlreiche Wörter mit Deminu-

1 Ozols, ib., sagt, daß in diesen Texten der Diphtong ie nicht vom (kurzen, langen, schmalen, breiten) $e$ unterschieden wird. 
tivendung, aber ohne deminutive Bedeutung1. Daß das auch in diesem Falle so ist, zeigt der lateinische Kontext des Stribiňs, in dem er vom Deum Equorum, quem vocant Dewing Vschinge spricht. Andererseits ist klar, daß wenn Stribiņš die lettische Verkleinerungsform schreibt, er dieses Wort so auch gehört hat. Mit anderen Worten: er hat mit seiner Meldung ein unzweifelhaftes Zeugnis dafür gebracht, daß die Letten, als er sie in der betreffenden Gegend besuchte, dieviņš $\bar{U}$ sin̨š kannten. Im Weiteren wollen wir uns mit dem religiösen Inhalt dieses Ausdrucks befassen. Hier ist nur noch auf parallele Sprachbildungen aus der annähernd gleichen Zeit zu verweisen, wo es im Protokoll eines Hexenprozesses 1584 Dewigen Perkone und Dewinge Sete heißt'. In beiden Ausdrücken finden wir den uns bekannten Dewing in den korrumpierten Formen Dewigen und Dewinge an Stelle des richtigen dieviňs. Das Interessanteste aber ist, daß auch in diesem Falle dievinus als Gattungsname verwendet wird, das eine Mal in Verbindung mit dem wohlbekannten baltischen Gott Pērkons ${ }^{3}$, das andere Mal mit einem Wort nicht zu bestimmender Bedeutung. Dies festigt weiter die Überzeugung von der Richtigkeit des von Stribiṇš gehörten und niedergeschriebenen.

2.1.3. Der Text des Stribiṇš ist auch in seinem Inhalt bedeutsam. Wir erfahren, daß Uিsiņš der Pferdegott ist. Wichtig ist der Hinweis, daß ihm Opfer gebracht worden sind, wobei das in einer bestimmten Weise erfolgte. Dreierlei wurde geopfert. Es konnte Geld sein, nämlich 2 Münzen, zwei Brote bzw. Brotstücke und ein Stückchen Speck. Beim letzten wird auch angemerkt, daß dieses ins Feuer geworfen wurde. Das ergibt eine recht deutliche Vorstellung vom Inhalt des Opfers wie von der Art desselben. Nicht mitgeteilt wird freilich, zu welcher Jahreszeit das Opfer erfolgte, ebenso wenig wird der Ort des Opfers genannt. Nur aus dem weiteren Wortlaut bei Stribiņš läßt sich entnehmen, daß in der freien Natur geopfert wurde.

Insgesamt können wir sagen, daß der Text des Stribiņš eine sehr bedeutende Quelle für das Verständnis des U̦siņš-Kults ist. Außer den Lücken bezüglich Ort und Zeit muß gesagt werden, daß dieser Text keine Angaben darüber enthält, was das zur Benennung des Pferdegottes dienende Wort $\bar{U} \sin s ̌$ eigentlich bedeutet.

2.1.4. Mehr als hundert Jahre später erscheint 1725 in den Nachrichten der Jesuiten nochmals Ūsinšs. So heißt es in Litterae annuae Residentiae

1 Darüber Endzelīns 1951, $313 \mathrm{~s}, \S 152$; auch Gramatika 1, $119 \mathrm{~s}, \S 160$, 10; Biezais $1961,33$.

2 Zeiferts 1957, 1, 258. Cf. auch Ozols 1965, 63; Volteris, 1907, 165, liest Dewinge Strele.

3 Cf. Biezais 1972, 92 ss. 
Duneburgensis: Jam crassa in quibusdam Livoniae angulis veri Numinis inter agrestes reperitur ignorantia, ut praeter Penates, Dryades, Nereides, et caetera monstra deorum, pecoribus etiam suum cuique speciei assignantes, praepositos colant deastros. Auditos est itlic praeses equorum Usins, dea pecudum Biruta, genius suum quidam Tenis, orcinianis commentis celebrari $^{1}$. In diesem Text finden wir den Namen Usins. Wir wissen nicht, wer der Verfasser dieses Textes ist. Aber die Form des Namens schafft keine Schwierigkeit, ihn mit dem 1606 erwähnten Wesen Dewing Vschinge zu identifizieren. Es scheint, daß die Endung -ns nur eine Bestätigung für die Schwierigkeit ist, die bei der Aussprache und der Schreibung der lettischen Endung -iņš bestand. Beim Inhalt ist zu beachten, daß der Text eine stärkere Ablehnung der örtlichen vorchristlichen Traditionen und deren Gottheiten nachweist, indem er diese monstra deorum nennt ${ }^{2}$. An die Stelle von Stribiňš Deus equorum ist jetzt praeses equorum getreten.

Der Prozeß des Synkretismus ist weiter fortgeschritten, deshalb war es nicht mehr angemessen, Ūsiñš als deus zu bezeichnen. Der Text zeigt auch, daß die Jesuitenpatres nicht mehr in der Lage waren, christliche Vorstellungen von vorchristlichen zu unterscheiden, denn sie nennen im gleichen Atemzug auch die durch die Volksetymologie verwandelten katholischen hl. Biruta und Tenis, die in Wahrheit die hl. Brigitta und der hl. Antonius sind. Jedenfalls wird durch diese in den Annalen der Jesuiten von $1725 \mathrm{zu}$ findende Nachricht über den praeses equorum Usiņ̌ die Kontinuität dieser Tradition bestätigt.

2.2.I. Die nächste Quellengruppe, die Nachrichten über Usingš bringt, ist lexikographischen Charakters. Die frühesten lettischen Wörterbücher erscheinen schon ab 1638. In diesen ersten Wörterbüchern ist, wie auch später, Usiņš nicht erwähnt. Das erste Mal erscheint ex in Langes Wörterbuch 1772 mit der ganz kurzen Angabe: „Uhsinss St. Jürgen“‘3. Zur Schreibung ist zu sagen, daß das - $h$ - die Länge des Vokals - $u$ - bezeichnet. Diese Kennzeichnung der Vokallänge ist eine schon in den ersten gedruckten lettischen Schriften aus dem Deutschen übernommene Tradition ${ }^{4}$. Lange hat dem Wort einen Asteriskus beigesetzt, was nach seiner Angabe ,seltene Wörter" bedeutet. Mit anderen Worten, er hat dazu keine näheren Angaben zu machen vermocht. Seine einzige Erklärung ist, daß Uিsinšs St. Jürgen

1 Fontes 1, 391.

2 Kleijtjens hat besonders betont, daß die Jesuiten in dieser Zeit ,einen besonders schonungslosen, radikalen Kampf" um die Zerstörung der Reste der alten Religion geführt hätten, indem sie heilige Haine abholzten usw. (cf. Fontes 1,252).

3 Lange 363. Über Lange und dessen Arbeit hat Ärons, 1921, geschrieben und sein Wörterbuch hat Zemzare, Daina, 1961, 130 ss, ausgewertet.

${ }_{4}$ Cf. Ozols 1965, 78. 
bedeutet, daß er also mit hl. Georg identisch ist. Die Schreibweise unterscheidet sich von der bei Stribiņš dadurch, daß hier das richtige palatalisierte - $n$ - geschrieben ist; gleichzeitig fehlt aber das -̌̌s, an dessen Stelle -s steht. Es ist schwer zu erraten, wie sich das erklärt.

2.2.2. Der Name Ūsiñš ist zwei Mal auch in Stenders Arbeiten zu finden. So steht in der Arbeit von 1783: „Uhsinsch, swehts uhsinsch der Bienen Gott (Von uhzas, der Bienen gelbe Wachshosen). "1 $\mathrm{Er}$ wiederholt sich nochmals 1789 noch kürzer, uhsin,sch, der Bienengott" 2 . Beim ersten Text ist anzumerken, daß das in damaliger Schreibweise geschriebene Wort phonetisch der heute gesprochenen Wortform entspricht. In den Texten besteht insofern ein Unterschied, als das erste Mal ein nichtpalatalisiertes - $n$ auftritt, im zweiten aber das richtige palatalisierte. Daß im ersten Fall nur ein Druckfehler vorliegt, ist auch daran zu erkennen, daß auch in einem weiteren 1789 veröffentlichten Text, das Wort richtig mit palatalisiertem - $n$ - abgedruckt ist. Die Schreibweise stimmt auch fast vollständig mit der obengenannten Langeschen überein.

Stender gibt dem Wort auch eine etymologische und eine semantische Erklärung. Nach seiner Meinung ist das Wort etymologisch mit uzzasHosen zu verbinden. Dieses im Lettischen gebräuchliche Wort ist zweifelsohne ein Germanismus, was einleuchtet, weil auch im Livischen (üzed, üžed), im Estnischen (uusad pl.) und im Schwedischen der Estlandschweden (huso) dieses Wort auftritt ${ }^{3}$. Dieses Wort ist zur Bezeichnung von Hosen schon im allerersten lettischen Wörterbuch 1638 anzutreffen ${ }^{4}$. Es muß ins Lettische schon früher, wohl im Mittelalter nach Ankunft der Deutschen in Lettland eingedrungen sein. Eine genauere Datierung ist nicht möglich. Der Gottesname Ūsiṇ.s würde durch Substantivierung einer Eigenschaft dieses Gottes entstanden sein, er wäre dann der mit Hosen bekleidete Gott, also der Behoste.

Stender geht mit seiner semantischen Erklärung noch weiter und bezeichnet Usinšs als den Gott der Bienen. Man hätte ihn sich als behost vorgestellt, weil die Bienen gelbe Wachshosen haben. So hätte dieser Gott seinen Namen bekommen. Im Unterschied zu Lange sagt Stender nichts über eine Identifizierung mit hl. Georg.

1 Stender 1783, 271. Hier ist anzumerken, daß jetzt und auch später bei der Trans. literierung gestrichenes $s$ und $s c h$ und nichtgestrichenes $s$ und $s c h$ in Fraktur gedruckten Texten durch $s$ und $s$ bzw. durch $z$ und $z$ ersetzt wurde.

2 Stender 1789 1, 335.

3 Cf. Zëvers $234 \mathrm{~s}$; auch ME 4, $410 \mathrm{~s}$; Zemzare, Daina 1961, $463 \mathrm{~s}$. Ebenso ist unter Vermittlung von Finnlandschweden das Wort ins Finnische (housut) eingedrungen (Cf. Wiget 259).

1 Mancelius 74, 178; auch Langius 322; Lange 2, 363; Stender 1789 1, 335; Ulmann 320 . 
Bezüglich der Behauptung Stenders ist auf zweierlei zu verweisen. Erstens kann, wenn der Name Ūsiņš eine Entlehnung aus dem Deutschen ist, dieser nicht der ursprüngliche Name des Gottes sein, weil er ein vorchristlicher Gott ist; es sei denn, man hält es für möglich, daß er erst in einer Zeit entstanden ist, als die Letten schon in Berührung mit den Deutschen waren, also nach dem 13. Jh. zur Zeit des Synkretismus. Zweitens ist auf den tiefen Widerspruch zwischen Stenders eigener Schreibweise und seiner semantischen Erklärung zu verweisen. Er schreibt das Wort Ūsinšs sehr richtig mit -s-, behauptet aber, es sei etymologisch von $\bar{u} z a s$ mit $-z$ - abzuleiten. Da hat Stender sich geirrt. Die beiden Wörter sind etymologisch ohne Beziehung. Jedes hat seine eigene Wurzel. Es wäre aber zuviel verlangt, daß er das unter den Umständen seiner Zeit hätte einsehen können. Es scheint, daß die phonetische Ähnlichkeit ihn zu der irrtümlichen etymologischen Inbeziehungsetzung verführt hat.

Weiter ist der Ausdruck swehts uhsinsch, den Stender dem Worte üsiňs beigegeben hat, der Aufmerksamkeit wert. Wir haben schon im Zusammenhang mit der von Stribiņš benutzten Wortgruppe Dieviņš Ūsinš gesagt, daß sie einer besonderen Analyse bedürfe. Dasselbe gilt für die Wortgruppen svēts üsiňs. Eine solche Analyse aber ist nur mit Kenntnis allen zugänglichen Materials möglich, deshalb werden wir später zu diesen Ausdrücken zurückkehren.

2.2.3. Fast hundert Jahre später, 1872, erschien Ulmanns Wörterbuch. Auch darin finden sich Angaben über Usiņš. ,,Uhsini, Georgi, uhzinu deena, Georgi-Tag, uhzinu meezchi, Georgi-Gerste. In Südlivland bis Kreuzburg [Krustpils]. Es scheint eine Vermengung eines heidnischen Patron's der Pferde mit dem christl. St. Georg statt gefunden zu haben. Uhsinsch, der Bienengott, St. Man soll auch jetzt in einigen Gegenden Kurlands mazais Uhsinsch für Bienengott hören. Kronw. "1 Hier ist gleich bezüglich der Schreibweise anzumerken, daß das in den Wortgruppen , uhzinu deena" und ,uhzinu meezchi" anzutreffende -z-als Druckfehler anzusehen ist, da zu Anfang und auch weiterhin das Wort Usinš mit dem gestrichenen Fraktur -s- geschrieben ist. Zum Inhalt ist anzumerken, daß Ulmann, wie die Buchstaben $S t$. zeigen, das in Stenders Wörterbuch von 1789 gesagte unverändert abgedruckt hat. Die Behauptung hat er durch den Hinweis ergänzt, daß in einer der Provinzen, nämlich in Kurzeme, mazais $\bar{U} \operatorname{siņš,~der~kleine~}$ Ūsinšs, zu hören sei, und $\mathrm{da} ß \mathrm{ihm}$ diese Angabe von dem Seminarlehrer in Dorpat Otto Kronwald [Kronvalds] zugekommen sei, der aus Kurzeme stammte ${ }^{2}$. Kronvalds mag in seiner Heimat einen solchen Ausdruck gehört

1 Ulmann 320.

2 Kronvalds (1837-1875) ist ein bekannter Mitstreiter in der Zeit des nationalen 
haben, es ist aber auch nicht auszuschließen, daß Kronvalds als Lehrer seiner Zeit Stender gut gekannt hat und unter dessen Einfluß vom Bienengott sprechen konnte.

Daneben kehrt Ulmann von neuem zu der sehr kurzen Anmerkung Langes von 1772 über die Identität von Usinsš und hl. Georg zurück. Er hat in seinem Wörterbuch, wie wir lesen, in diesem Zusammenhang die Bemerkung angefügt, es habe eine Vermengung des heidnischen Pferdepatrons mit hl. Georg stattgefunden, wobei er diese Erscheinung auf Südlivland begrenzt. In Wahrheit neu und bisher unbekannt ist nur die Ergänzung über die Verbindung des Wortes Ūsiņš mit der Zeit. So bedeutet Ūsiņi pl. bzw. Usinu diena 'Georgi, Georgstag', wie auch in gleicher Bedeutung von üsinu miež $i$ gesprochen wird, von Gerste also, die um den Georgstag gesät wird. Für diese Angaben hat Ulmann einen Brief benutzt, den ihm der Vorgänger des uns wohlbekannten Pastors Auniņš in der Gemeinde Cesvaine Müthel (*1805) geschrieben hat. Im Brief vom 20. Juli 1870 schreibt dieser: ,Im Sesswegenschen [Cesvaine] Kirchspiel und, soweit mir bekannt geworden, im ganzen südöstlichen Teile des lettischen Livland von Laudohn [Laudona] bis Marienburg [Alüksne] nennen die Letten noch heutigen Tages den 23. April bald Jurǵga-deena, bald Uhsing-deena, und die Zeit, in welche dieser Tag fällt, Jurǵi oder Uhsiņi. Sie sagen uz, ap, pēc Jurǵeem oder Uhsiņeem, wie gleichermaßen uz, ap, pēc Jahṇeem, Miḳeleem, Mahrtị̧eem usw. “1 Damit ist unmißverständlich eine lebendige Tradition in dem erwähnten Gebiet bestätigt. Der Name Usiņš wird mit einer bestimmten Zeit bzw. einem bestimmten Tage verbunden. Die Bezeichnung Ūsinš̌tag wird wechselweise mit Jurǵi und Jurǵa-deena, d. i. mit Georgi und Georgstag benutzt.

Danach sind weitere Wörterbücher erschienen, die man eventuell erwähnen könnte. In erster Linie wäre hier über ME zu sprechen, aber darin hat die gelehrte Diskussion, auf die wir später besonders eingehen, schon starken Einfluß hinterlassen. Deshalb können wir die Analyse des Lexikographischen Materials mit der Arbeit von Ulmann abschließen.

2.2.4. Zusammenfassend können wir sagen, daß das lexikographische Material die schon von Stribiņš vermerkte Tatsache bestätigt, daß ein Gott Ūsiņš bekannt war. Weiter bietet es die Möglichkeit, die Aussprache des Wortes Vschinge bei Stribiṇš als Ūsiņ̌s zu präzisieren, bringt aber gleichzeitig eine neue Schreibweise des Wortes mit stimmhaftem $z$, nämlich

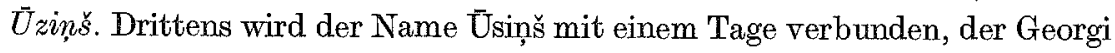
entspricht. Viertens tritt ein neuer Wesenszug des Ūsiņš auf. War er bis dahin nur als Pferdegott bekannt, so ist er jetzt auch als Bienengott ver-

Erwachens. Literaturhinweise über seine Person und seine Tätigkeit finden sich in Vēsture 2, 496; Kundziṇš $118 \mathrm{ss,} 238 \mathrm{ss.}$

1 Auniņs 1881, 8. Der Brief ist auf S. 34 vollständig abgedruckt. 
merkt. Schließlich ist anzumerken, daß die Tradition sich seit 1606 lebendig erhalten hat.

2.3. Schon im vorigen Abschnitt haben wir die Motive genannt, die das Interesse des Auniņš begründeten und ihn zu seinen Forschungen über Ūsiņš veranlaßten. Es scheint, daß der Rigasche Stadtbibliothekar Berkholz mit der Frage, mit der er sich an den damaligen Pastor zu Dikḷi Auniņš gewandt hat, auch an andere herangetreten ist. Ohne aus den Grenzen von Mutmaßungen herauszutreten, kann man annehmen, daß er sich auch an den Bischof Ulmann gewandt hat, der seinerseits bei Müthel, dem Vorgänger des Auninš als Pastor in Cesvaine, nachgefragt hat. Zu einer solchen Überlegung veranlaßt das Datum des Briefes, den wir hier veröffentlichen, der 20. Juli 1870. Danach veröffentlichen wir einen weiteren Brief, den der Pastor der benachbarten Gemeinde Lazdona Gaehtgens (1847-1919) dem Auniņš geschreiben hat. Beide Briefe sind von gelehrten Männern geschrieben, die auf das Problem Ūsinšs gestoßen waren. Sie enthalten einesteils direkt empfangene Nachrichten über diese Erscheinung, es fehlt andererseits darin auch nicht an persönlichen Reflexionen. Will man die dort gemachten Angaben werten und sie als Quellen heranziehen, ist dieser Umstand besonders im Auge zu behalten.

2.3.1. Müthel schreibt am 20. Juli 1870 an Ulmann: ,1) Im Sesswegenschen [Cesvaine] Kirchspeil und, soweit mit bekannt geworden, im ganzen südöstlichen Teile des lettischen Livland von Laudon [Laudona] bis Marienburg [Alūksne,] nennen die Letten noch heutigen Tages den 23. April bald Jurǵa-deena, bald Uhsiṇ-deena und die Zeit, in welche dieser Tag fällt, Jurǵi oder Uhsiṇi. Sie sagen, us, ap, pehz Jurǵgeem oder Uhsiṇeem, wie gleichermaßen us, ap, pehz Jahņeem, Miķeļeem, Mahrtiņeem u. s. w. Der Nom. Sing. lautet, wie ich meine, im lettischen Munde stets wie Stender schreibt: Uhsinssch, nicht aber wie Lange schreibt: Uhsị̧s. Noch weniger möchte hier jemals aus lettischem Munde Uhschinssch, Uhschị̣-deena oder Uhschiņ-tirgus gehört worden sein.

2) Aus Allem, was ich über den Uhsinsch habe in Erfahrung bringen können, muß ich schlißen, daß zwischen ihm und dem Ritter St. Georg gar kein tatsächlicher Zufammenhang anzunehmen ist. Uhsinsch muß vormals ein Götze der heidnischen Letten gewesen sein. Nachdem diese das Christentum angenommen hatten, mag die ungefähre Gleichzeitigkeit des St. Georgstages und des Uhsin-Festes die Veranlassung dazu gegeben haben, daß die Namen beider mit einander verbunden wurden, auf ähnliche Weise wie die Namen Lihgos und Johannis des Täufers.

3) Als Götze der alten Letten hatte Uhsiṇsch ohne Zweifel auch seinen eigentümlichen Cultus gehabt, von welchem sich, gleichwie vom rormaligen 
Cultus anderer lettischer Götzen, nur das gebräuchlich gewesene UhsingFestmahl bis auf unsere Zeit erhalten hat. Letzteres hat sich von anderen lettischen Festmahlen vornehmlich dadurch unterschieden, daß es ein Frühmahl gewesen ist, an welchem lediglich die Gesindesbewohner mit strenger Ausschließung fremder Gäste haben teilnehmen dürfen und zu welchem ein im Pferdestall geschlachteter Hahn gebraucht worden sein soll. Solche Sitte ist am Uhsin-Morgen noch vor einigen Decennien in vielen hiesigen Gesinden aufrecht erhalten worden. Da dieselbe nicht vielleicht noch z. B. im Lubahnschen [Lubāna] heimlich fortbesteht, muß ich dahingestellt sein lassen.

4) Daraus, daß der Uhsin-gailis (Uhßing-Hahn) im Pferdestall geschlachtet worden, daß der Laudohnsche Uhsin-Tirgus ein Pferdemarkt ist und daß, wie mir gesagt worden, noch heutigen Tages mancher Lette beim Anblick eines schönen Pferdes seine Bewunderung desselben durch den Ausruf: 'Ak, Uhsiṇ!' 'Ak, Uhsiṇ' (o Uhßing! o Uhßing!) zu erkennen gibt u. s. w. glaube ich den Schluß ziehen zu müssen, daß Uhsinssch vornehmlich als Pferdegott von den heidnischen Letten verehrt worden ist. Dabei kann Stender ihn jedoch immerhin mit Recht als Schutzpatron der Bienen bezeichnet haben, denn am St. Georgsmorgen sollen in hiesiger Gegend noch vor nicht sehr langer Zeit die Bienenzüchter Kuchen (Plahziṇi oder Karaschi) auf ihre Bienenstöcke gelegt haben.

5) Falls die alten Letten sich den Uhsinsch als ihren Pferdegott unter dem Bilde eines gewaltigen Reiters gedacht haben, der unter anderen Eigenschaften auch mit einem Schnauzbart geziert gewesen sein mag, so scheint mir sein Name von Uhsa (uhsas - Schnurbart) abgeleitet werden zu können und würde soviel bedeuten als uhsains (der Schnurbärtige). "1 Der Brief berührt mehrere wichtige Fragen nach dem Wesen des Üsinšs und seinem Kult, insbesondere nach dem Letzteren. Das ist eine Frage von entscheidender Bedeutung. Zu ihr können wir erst nach der Analyse des gesamten uns zugänglichen Materials zurückkehren. Hier verweisen wir nur auf Momente, die mit dem Namen Ũsinš verknüpft sind, und die Vermutungen über dessen Funktion und Substitute. Bezüglich des Namens hat Müthel einiges zu Beachtende geäußert. Er unterstützt die Schreibweise Stenders, nämlich $\bar{U}$ sin̨s, und bekräftigt damit, daß die richtige Aussprache des Namens eben diese ist. Er hat auch schon bemerkt, daß die Schreibweise Uhsins bei Lange, wie wir schon erwähnten, nicht richtig sein kann. Daran ändert die Bemerkung nichts, die Auniņ̌s zu dieser Feststellung Müthels macht: „Lange wird wohl (!) seinen Uhsins ganz ebenso ausgesprochen haben, wie Stender seinen Uhsiņš. “2 Diese Anmerkung des Auniņš

\footnotetext{
$1 \mathrm{Ib}$.

2 Ib. 9.
} 
ist insbesondere deswegen ohne Bedeutung, weil Lange in anderen Wörtern bei seiner Schreibweise das sch bzw. š kennt und richtig verwendet.

Noch bedeutsamer ist Müthels Hinweis, wonach die Letten niemals Uhschinsch, Uhschin-deena oder Uhschin-tirgus sagen. Das ist besonders wichtig, weil wir schon in der Schreibweise des Stribiņš den Sammelbuchstaben -sch- antrafen und dabei darauf hingewiesen haben, daß aus dem lateinischen Text, dessen Aussprache nicht zu bestimmen ist. Dieser Hinweis von Müthel bestätigt, daß die hundert Jahre zurückliegende Schreibweise von Lange und Stender und die Aussprache mit -s- die richtige ist. Das nährt die Zweifel an der Richtigkeit der bei Stribiṇš anzutreffenden Schreibweise mit -sch-.

Weiter erklärt Müthel die wechselweise Verwendung der Namen von Ũsinšs und hl. Georg mit dem zeitlichen Zusammentreffen der ihnen geweihten Feste. Gerade deshalb wurden ,die Namen beider miteinander verbunden". Weiter ist auch sein Hinweis wichtig, daß Stenders Behauptung, Ūsiņš sei der Bienengott, richtig sein kann und kein Widerspruch dazu ist, daß er zugleich auch der Pferdegott ist, denn tatsächlich hätten die Imker noch vor nicht langer Zeit zu Georgi Kuchen als Opfer auf die Bienenstöcke gelegt. Diese seine Begründung stimmt freilich mit dem von Stender selbst Gesagten nicht überein, der ihn ,mit der Bienen gelben Hosen" verknüpft,

2.3.2. Der zweite Brief stammt vom Pastor der Gemeinde Lazdona Gaehtgens. Wr ist an Auninšs gerichtet. „Am Uhsiņ-Tage haben die Männer in der Morgenfrühe im Stall einen Hahn geschlachtet, denselben ausgekocht und selbst aufgegessen; die Weiber haben keinen Teil daran gehabt. In der Nacht haben sie dann die Pferde zum ersten Mal auf die Weide geführt, ein Feuer angezündet und Fleisch, Bier und Eier genossen. Für jedes Pferd haben sie ein besonderes Ei bezeichnet. Ist es beim Kochen geplatzt, so ist es ein Zeichen gewesen, daß dem betreffenden Pferde im künftigen Jahre Unheil drohe. 'Nu manam sirgam ne-ees labi!' (jetzt wird, es meinem Pferde nicht gut gehen) so hat der Eigenthümer dann gerufen. Hernach haben sie sich dann einen Pantags (Pfankuchen von Eiern mit Speck) gebacken und ihn nebst Fleisch und Bier verzehrt. Dazu sind dann auch die Weiber und Kinder zugelassen worden. Die Männer aber haben allein das Mahl bereitet. Wenn die Mahlzeit fertig gewesen, so hat der Aelteste das gewöhnliche Tischgebet gehalten. Darauf aber hat er gleich den Uhsin angerufen: 'Lai tad nu Uhsị wezais tehws sarga sirgus un glaba no wisas nelaimes, no wilkeem, no slimibas etc.' (So möge nun Altvater UhBing die Pferde beschützen und sie bewahren vor jedem Unglück, vor den Wölfen, vor Krankheit etc.). Dann hat der Aelteste zuerst den Löffel in den Pantags gesteckt und nun erst haben auch die Anderen angefangen zu essen. Nach 
dem Essen haben sie wieder gesprochen: 'Lai tad nu Uhsin tehws tohs sirgus glaba; nu jau Peeguḷneeks (d.h. Uhsinssch) mahjâ!' (So möge denn Vater Uhßing die Pferde behüten; jetzt ist ja der Nachthüter (d. h. Uhßing) zu Hause. Damit sind ihm nun gleichsam die Pferde fürs ganze Jahr anvertraut gewesen. Wenn dann zu Michaelis oder zu Martini die Pferde wieder heimgeführt worden sind, haben sie wiederum einen Hahn geschlachtet. Das Blut des Hahnes haben sie in die Krippe auf den Hafer geträufelt oder haben damit ein Kreuz auf die Stallür gemacht. In Bezug auf diese Feiertage ist das Sprüchwort gebräuchlich gewesen: 'Tu laiku gaidi, laiks tewis gaida' (Du wartest auf die Zeit, die Zeit wartet auf dich) d. h. die bestimmten Festtage erwarten von Dir eine besondere Feier und besondere Gaben etc. Unter Praulen befindet sich ein Hügel, der noch jetzt Pantagu-kalninsch genannt wird weil auf ihm früher alljährlich bei der Feier des UhBingTages der Pantags zugereitet worden ist, während die Pferde rundumher geweidet haben."1 Zu diesem Brief ist anzumerken, daß er seinem Inhalte nach zu den später in dieser Arbeit zu behandelnden Fragen über das dem Ūsinšs geweihte Mahl und den damit zusammenhängenden Problemen gehört. Zum Namen des Uিsiņš selbst bietet er keine Angaben, da Auniņš, als er ihn in seinem Aufsatz abdruckte, denselben in Übereinstimmung mit der eigenen Schreibweise umgeschrieben hat, die er, wie wir gehört haben, besonders begründet.

Beide Briefe erhalten ihre Bedeutung als Quellenmaterial bei der nachfolgenden Erörterung des Problems. Bezüglich des Verständnisses des Namens Usingš ist allein Müthels Brief mit der Angabe bedeutsam, daß den Letten seiner Gegend der -š-Laut im Namen Üsinšs nicht bekannt ist.

2.4. Die umfangreichste, zugleich aber auch komplizierteste Gruppe Quellenmaterial ist die Folklore. Thre Verwertung ist mit zahlreichen quellenkritischen und methodischen Problemen verbunden. Meine Arbeit wird in diesem Falle nur dadurch erleichtert, daß ich mich mit diesen Fragen und Problemen schon in früheren Arbeiten befaßt habe. Um unnütze Wiederholungen zu vermeiden, habe ich im folgenden an entsprechender Stelle auf jene verwiesen und mich dabei auf das Notwendigste beschränkt, das erforderlich ist, um Mißverständnisse und vor allem eine unkritische Verwendung dieser Quellen zu vermeiden.

2.4.1. Am umfangreichsten ist das Material der Dainas². Die Anzahl der Dainas, in denen Üsinš direkt genannt wird, ist gut überschaubar. Deren

$1 \mathrm{Ib} .10 \mathrm{ss}$.

2 Die lettischen Volkslieder sind gewöhnlich vierzeilige Strophen. Sie haben in der internationalen Forschung, ahnlich wie spezielle Gestaltungen anderer Völker, auch eine eigene Bezeichnung ,,Daina", Pl. „Dainas" erhalten. 
gibt es etwa 110. Die Zahl ist jedoch nicht völlig sicher. Es fehlt nach wie vor an einem übersichtlichen Verzeichnis der Dainas, darum enthält die große Sammlung LD nur etwa 43 Texte. Dort kann auch ein Text abgedruckt sein in einer Abteilung in der er nach dem systematischen Inhaltsverzeichnis nicht zu erwarten ist. Gleichzeitig aber ist anzumerken, daß dieser Mangel so begrenzt ist, daß es sich auch nur um einen einzelnen Text handeln kann. Das bedeutet praktisch, daß ein solcher, das in dieser Arbeit aufgezeigte Ergebnis nicht verändern kann. Die in dieser Arbeit ausgewerteten Dainas sind in verschiedenen Ausgaben und über einen recht großen Zeitraum verteilt erschienen. Die ersten erschienen 1881, und die letzten gar erst 1955. Der zeitliche Abstand ist so groß, daß in ihm die Verhältnisse sich geändert haben, und damit in vielen Fällen auch die Vorstellungen über Ūsiņš. Das ist ein Umstand, der die Auswertung der Texte sehr erschwert. Es ist der Grund dafür, daß man nahezu jeden Text einzeln betrachten und dessen Bedeutung bewerten muß. In dieser Arbeit sind alle mir bekannten Texte über Usinšs vermerkt. Am Ende der Arbeit findet sich ein Verzeichnis, das darüber Auskunft gibt, auf welcher Seite der betreffende Text abgedruckt und analysiert ist. Texte, die nicht direkt ausgewertet wurden, sind, um sie zukünftiger Forschung zugänglich zu machen, im Verzeichnis nummeriert jedoch abgedruckt. Im Verzeichnis sind keine Texte aufgenommen, die sich nur in geringen orthographischen Eigentümlichkeiten unterscheiden, ebenso wird nicht erwähnt, daß oder wenn ein Text in anderen Ausgaben abgedruckt ist. Bei der Auswertung der Texte werden nach Möglichkeit inhaltlich ähnliche Texte um einen Grundtext vereint, wobei die anderen als Varianten bezeichnet werden, und nur die Wörter oder Ausdrücke gedruckt werden, die unterschiedlich sind. Alle Grundtexte sind fortlaufend nummeriert, hinter der Nummer des Grundtextes steht, durch Kommas getrennt, die Nummer der Variante. Hinter den lettischen Text ist ein Buchstabe und eine Zahl, oder nur eine Zahl gedruckt, die anzeigen, aus welcher Sammlung oder anderer Quelle er entnommen wurde.

2.4.1.1. Wie schon im vorigen Abschnitt erwähnt, hat Auniņš im Dezember 1880 in der Jahresversammlung der Lettisch-literärischen Gesellschaft, der zu damaliger Zeit bedeutsamsten wissenschaftlich orientierten Vereinigung, seinen Vortrag gehalten, und dabei versucht, die Frage ,Wer ist Uhsing?" zu beantworten. Im darauffolgenden Jahre wurde der Vortrag veröffentlicht, wobei, wie Auniņš selbst sagt, er alle ihm bekannten Texte abgedruckt hat. Deren hat er 42. In der Zeit zwischen dem Vortrag und dessen Veröffentlichung erschienen in der Zeitschrift „Pagalms" zwei Ūsiṇš-Texte, die Auniṇš dann auch mit aufnahm² ${ }^{1}$. Eines davon ist in unserem

1 Eine Übersicht über die verschiedenen Ausgaben der Dainas bietet Biezais I961 a. I ss; auch Ozols 1938, 34 ss. 
Verzeichnis (50) mit A 60 bezeichnet, das andere, A 61, ist als 1.V. an A 14 angeschlossen (12). Später hat Auniņš in einer Schrift von 1905 noch weitere 17 Texte veröffentlicht. Damit hat er insgesamt 61 Texte veröffentlicht. Er selbst hat aber darauf hingewiesen, daß die Unterschiede zwischen manchen Texten so gering sind, daß sie bloß als Varianten anzusehen sind. Deshalb werden sie beim Abdruck in dieser Arbeit als Varianten verzeichnet.

Die 1881 veröffentlichten Dainas mit dem Namen Ūsinšs sind das erste veröffentlichte Material dieser Art, ungeachtet dessen, daß einzelne Dainas schon seit der 2. Hälfte des 18. Jhs. und die ersten Sammlungen schon im 1. Jahrzehnt des 19. Jhs. erschienen. Das ist an sich schon eine Tatsache, die bei der Verwertung dieser Texte in Betracht gezogen werden muB.

Den ersten 42 veröffentlichten Liedern hat Auniṇš die Bemerkung beigefügt: „Nicht alle diese hier mitgeteilten UhBing-Lieder sind von gleichem Werte für die Ermittelung der Vorstellungen und Ideen, die mit dem Namen 'Uhßing' verbunden worden sind. Weil aber den bisherigen Sammlern der lettischen Volkslieder die UhBing-Lieder unbekannt geblieben waren, habe ich sämtliche UhPing-Lieder, die ich überhaupt habe finden können, in diese meine Sammlung aufgenommen. "1 Das ist nicht nur eine lobenswerte Offenheit, sondern auch ein klar ausgesprochenes Urteil über den unterschiedlichen Wert dieser Texte. Ungeachtet aber der unmißverständlichen Haltung von Aunị̌s selbst haben diese Texte einige Jahrzehnte währende Polemik über deren Wert und Bedeutung für die Klärung der Frage nach Ūsinšs ausgelöst. Die Polemik begann nach 22 Jahren. Unterdessen war eine neue Generation akademisch gebildeter lettischer Linguisten und Literaturhistoriker herangewachsen. An den ersten Platz hatte sich Endzelins geschoben. Er hielt 1903 in derselben wissenschaftlichen Gesellschaft, in der Auniņš seinen Vortrag gehalten hatte, einen Vortrag über Ūsinšš2. Dieser war in Wahrheit eine scharfe Polemik gegen Auniņš. Lassen wir einstweilen die Frage nach dem Wesen des Ũsiņš beiseite, und betrachten nur die Quellenkritik, der Endzelins in seiner Arbeit nur eine sehr geringe Stelle zuweist. Die aber hat bei der weiteren Erörterung der Frage durchaus ihre Bedeutung.

Endzelins beanstandet, daß Auniṇš bei den von ihm veröffentlichten Texten nicht angibt, von wem er sie erhalten hat, denn, ,es ist sehr bedeutsam zu wissen, welche Person das eine oder andere Lied mitgeteilt hat "3. Er verweist insbesondere auf das hier veröffentlichte Lied 38, das Auniņš

\footnotetext{
1 Auniṇ: 1881,23 s.

2 Das ist in der Zeitschrift Ap., 1903, Nr. 2, abgedruckt und dann bei Endzelins 1971,268 ss.

3 Endzelīns 1903, 271. Er hält Minna Freimane für eine besonders unglaubwürdige Übermittlerir
} 
für gut verständlich hält, das Endzelins aber für ,,im Rhythmus wie im Inhalt" bedenklich ansieht. Er würde diesen Text nur zu interpretieren wagen, wenn er sicher wäre, daß „Auniņš diesen Text von einer zuverlässigen Person aufgeschrieben hat." Endzelīns begründet seine Forderung, die Quellen aufzuzeigen, mit dem für die damalige Zeit sehr ungewöhnlichen Hinweis: „Als wir Letten auch unsere Mythologie haben wollten und die Nachrichten über die alte Religion so wenige waren, fanden sich bekanntlich von Patriotismus [gemeint ist Nationalismus] berauschte Personen, die entweder irgendwelche Götterchen erdachten, oder über den einen oder anderen der tatsächlich einmal lebendigen Götter zu deren Ehre Lieder verfaßten." 1

Die Forderung von Endzelīns nach Quellennachweis ist begründet. Er hat auch ganz richtig die Gefahr gesehen, die unter dem Einfluß nationaler Romantik über Pseudogötter verfaßte Texte darstellen. Den Text 38 aber hat er zu leichtfertig als in Rhythmus und Inhalt bedenklich qualifiziert. Eine solche Behauptung ist belanglos, weil Endzelīns nicht aufzeigt, aus welchen Gründen ihm der Inhalt ,anstößig“ erscheint. Dasselbe gilt für den Rhythmus.

Im gleichen Jahr trat auch Šmits mit seinen Einwänden gegen die von Auniņš publizierten Úsiňš-Lieder hervor. Seine Äußerungen waren nicht nur durch diese Texte, noch stärker durch die von Lautenbachs verfaßte Schrift über die Religion der alten Letten veranlaßt, die sich auf die Dainas beruft, und in der viele Pseudogötter aufgeführt werden². Er sagt: ,Wenn ich jetzt die Lieder über Ūsinšs und die „Volks"-Lieder des Herrn Lautenbachs zusammenlese, finde ich zwischen ihnen eine so große Ähnlichkeit, daß ich nicht mehr an einer Fälschung zweifle. Die Lieferanten der Lieder werden auch Herrn Auninss betrogen haben. In unseren gewöhnlichen Volksliedern ist bekanntlich jede vierte Silbe kurz. Wo Ausnahmen auftreten, sind das zweifelsohne Fehler, die immer leicht zu korrigieren sind. In gefälschten Liedern, so auch in den Liedern über Usiņš sind derartige Ausnahmen häufig, und die Fehler sind gewöhnlich nicht zu beheben, auch wenn man den Satzbau verändert. "3 Dann bietet Smits mehrere Beispiele aus den Texten von Auniņš, die derartige Mängel aufweisen. Weiter verweist er auf eine größere Anzahl von Wörtern in diesen Texten, die entweder aus fremden Sprachen entlehnt oder Neubildungen sind. Er bemerkt auch, daß diese Lieder Vorstellungen enthalten, die nur in neuester Zeit entstanden sein können. Unter Berücksichtigung aller dieser Umstände folgert er, „daß manche Wörter, Begriffe und Konstruktionen an die Neuzeit

1 Ib. 272.

2 Cf. Lautenbachs 1901, 101 ss.

3 Smits 1903,170 s. 
erinnern und nicht in langer Vergangenheit entstanden sein können“1. Die Einwendungen von Smits gegen die Texte von Auniņš, die er ebenso wie die Texte von Lautenbachss für ,Fälschungen“ aus neuerer Zeit hält, sind klarer und besser begründet als die in allgemeinen Worten ausgedrückten Einwände von Endzelins.

Was sagt nun Auniņš zu diesen Einwänden? Die Antwort erfolgte einige Jahre später. Er erlklärt, daß er mit der Forderung von Endzelīns, den Übermittler zu nennen, einverstanden sei, ,aber jetzt ist es leider zu spät, da die meisten der alten Frauen, denen ich mein Material verdanke, aus der Zeitlichkeit in die Ewigkeit hinübergegangen sind“‘2.

Weiter sagt Auniņš, daß er sich jetzt auf nur zwei noch lebende Frauen und einen Mann berufen könne. Er nennt diese dann auch bei Namen und gibt ihren Wohnort an. In diesem Zusammenhang ist sein Hinweis auf die erste Nachrichtengeberin über Ŭsiṇš der wichtigste: ,Von den beiden noch lebenden Frauen, denen ich meine Uhsiṇ-Lieder verdanke, ist die eine Greete Jaunosol [Jaunozola], [...] geb. 1835 den 10. Juli. Sie ist die erste gewesen, von der ich Uhsiņ-Lieder erhalten habe und durch die ich überhaupt zu einer Kunde davon gelangt bin, daß Uhsiņ-Lieder existieren. Die Männer, bei denen ich mich früher nach dem Uhsiņ-Mythus erkundigt hatte, hatten mir nur Mitteilungen über die Uhsin-Opfer machen können. Als ich später Einigen das eine oder andere Lied recitierte, da behaupteten sie allerdings, sie zu kennen. ${ }^{` 3}$

Zu der ersten Liederansagerin Grieta Jaunozola ist Auniņš nach wiederholter Polemik mit Endzelins und Šmits 1913 nochmals zurückgekehrt. Die in diesem Zusammenhang über sie und die Bemühungen von Auniṇ̌s um die Sammlung der Lieder gemachten Angaben sind sehr wichtig. Wir werden bei der Erörterung der Polemik von 1913 auf sie zurückkommen ${ }^{4}$.

Wenn nun Aunin̄š wenigstens drei der Liederansager der von ihm früher veröffentlichten Texte zu nennen vermochte, hätte zu erwarten gestanden, daß er die $Z$ weifel von Endzelinns zerstreuen könnte und mitteilen würde, welche der Texte von diesen Personen stammten. Er hätte ja unschwer bei diesen Personen rückfragen können, wenn er keine diesbezüglichen Notizen hatte. Aus anscheinend unerklärlichem Grunde hat Auniņš das nicht getan. Stattdessen veröffentlichte er einige neue Texte, teils Varianten von Liedern, die er schon veröffentlicht hatte, teils bis dahin unbekannte. Das erzeugte bloß verstärkten Verdacht gegen die Glaubwürdigkeit der von Auniņš

1 Ib. 171 .

2 Auniņš 1905, 8.

3 Ib. $9 \mathrm{~s}$.

${ }^{4}$ Cf. Auniņ̌ 1913, 19 s. 
veröffentlichten Texte ${ }^{1}$. Das hatte aber, wie wir später sehen werden, seine Gründe.

Wo Auniņš hätte konkrete Erläuterungen geben müssen, die dazu beigetragen hätten, die Zweifel an seinen Texten zu zerstreuen, hat er beacht. liche prinzipielle Erklärungen dargeboten, die als solche nicht zu bezweifeln sind.

Er schrieb: ,Jeder Sammler von Volksliedern, Mythen, Sagen und Märchen wird a priori zugeben müssen, daß er getäuscht werden kann. Es wird Fälle geben, wo der nüchterne kritische Sammler eine plumpe Erfindung leicht durchschauen kann, andere, wo man im Zweifel und Ungewissen bleiben muß, dann aber auch solche Fälle, wo jeder $Z$ weifel ausgeschlossen ist. Wenn solch ein altes Mütterchen freundlich lächelnd, ihrer Jugendzeit gedenkend, wo sie diese Lieder gelernt und gehört hatte, sie schlicht recitiert, da hat man wol keinen Grund mißtrauisch zu werden. Wie oft bekommt man auf die Frage: 'Bet ko tas nozīmē?' die Antwort: 'To mës nezinām, tā jau saimniece mūs mācīja dziedāt, kad ganos gājām.'

Aber auch zugegeben, daß das eine und andere Wort vielleicht von den Recitierenden verändert worden, ein unbekanntes durch ein bekanntes ersetzt worden ist, wie es uns die zahlreichen Varianten beweisen, so bleibt doch der Gesammtcharakter der Lieder unalteriert.

Ich habe nichts gegen die Forderung einzuwenden, daß bei jedem Liede oder Märchen der Name der Person genannt wird, die die Mitteilung gemacht hat. Aber ist das schon eine absolute Garantie, daß jede Täuschung ausgeschlossen? Wer bürgt mir dafür, daß Trihne Meedsin oder Greete Sapnis nicht ihre eigenen Phantasien mir mitgeteilt haben? Oder sollten sie vorher darauf hin vereidigt werden, mit ohne die Veränderung auch nur Eines Wortes das zu recitieren, was sie wirklich gehört haben? Es wird zuweilen auch falsch geschworen [...].

Ohne zu glätten und zu feilen, habe ich das Material über den UhsiṇMythus veröffentlicht, so weit es mir zugänglich war. Es wäre ein Leichtes gewesen, manches Lied von mancher Härte zu befreien. Daß an die Stelle früher gebrauchter Worte und Formen in späterer Zeit gebräuchlichere, bekanntere gesetzt worden sind, daß die lettischen Volkslieder im Lauf der Zeit großen Umwandlungen unterworfen gewesen sind, unterliegt keinem Zweifel; daß diese Lieder noch in der jüngsten Zeit zahlreiche Modificationen erlebt haben und beständig erleben, beweisen uns ihre zahlreichen Varianten."2

1 Das überrascht besonders, weil Endzelins direkt gefragt hatte, ob unter den Übermittlerinmen der Texte auch die erwähnte Minna Freimane war. Auniṇš hat auch auf diese direkte Frage nicht geantwortet.

2 Auniņš 1905, 12 s. Schließlich beschränkt sich Auniņš auf die Verteidigung seiner selbst (cf. 1905, 14). 
Einerseits antwortet Auniņš sehr richtig und nicht ohne Tronie, daß auch unter Eid gemachte Aussagen nicht immer wahr sind. Deshalb sind die aufgeschriebenen Aussagen in der Folklore aus prinzipiellen Gründen auch nicht absolut sicher. Andererseits bestätigt er nochmals, daß er das gesamte Material so dargeboten hat, wie es ihm zur Verfügung stand, ohne es irgendwie zu verändern. Mögen die Angaben von Auniņš über die konkreten Texte noch so unbefriedigend sein, gibt es doch keinen Grund, daran zu zweifeln, daß er sich vom guten Willen hat leiten lassen, das ganze ihm Zugängliche so darzubringen, wie es ihm vorlag. Ein Gewinn dieser Diskussion war es auch, daß man ein wenig Einblick in die Umstände erhält, unter denen Auniņš seine 42 Texte, die er später auf 61 ergänzte, erhalten hat. Die 1905 veröffentlichte Antwort auf die Kritik von Endzelins und Smits beendete die Diskussion über der Wert der Ūsiņš-Lieder von Auniņš dennoch nicht. $\mathrm{Zu}$ ihr kehrten fast gleichzeitig Endzelins und Smits wieder zurück.

Zuerst wandte sich Endzelīns nach den Erklärungen von Auniṇš der Frage nach Ūsiņš wieder zu. Err äußert aber nichts über den Wert der Quellen der von Auniņš veröffentlichten Ūsiņšs-Lieder, sondern behandelt nur die Etymologie und die eventuelle Herkunft des Namens. Seine Arbeit wollen wir später im Zusammenhang mit der Etymologie erörtern'. Smits hingegen befaßt sich in seiner 1911 veröffentlichten Arbeit überwiegend mit der Frage, ob die Üsinš-Lieder echt oder gefälscht sind ${ }^{2}$. Er gelangt zum Schluß, daß die von Auniņš veröffentlichten Lieder gefälscht sind. Zur Bezeichnung derartiger Lieder verwendet er neben dem Wort gefälscht als Synonyme: unecht, verdorben, verändert usw. Deshalb ist es hier am Platz, sich mit den von ihm genannten Motiven für seine Anschauung bekannt zu machen. Die Argumentation von Smits ist auch deshalb zu erwähnen, weil er selbst und andere sich in der Diskussion auf diese beruft. Er nennt verschiedene Motive für die Anschauung von der Verfälschtheit der Lieder des Auniņ̌s und macht Auniņš bezüglich der Lieder auch direkte Vorwürfe. Wir können uns hier nicht mit einer genauen Erörterung der Schrift von Smits befassen, sondern nennen nur seine Haupteinwendungen gegen die Ūsiņš-Lieder. Das erste Argument ist, daß drei verschiedene Forscher - Auniņ̌̆, Endzelins und Volteris - zu je einem anderen Ergebnis über das Wesen des Ūsiņ̌s gekommen sind, der erste habe nämlich erkannt, daß Ūsiņš ein Lichtgott sei, der andere behauptet, es handele sich um einen von den Deutschen übernommenen Hausgeist, der dritte sagt, es handele sich um einen unter dem Einfluß des russischen усень entstandenen Namen. Daraus folgert er:

\footnotetext{
1 Cf. unten S. 127 ss.

2 Er sagt mit negativem Pathos: ,,Gegen die Fälscher zu kämpfen, ist keine leichte Aufgabe, und wir können das nur mit vereinten Kräften."
} 
„In Anbetracht alles dessen haben wir ein Recht, an der Echtheit dieser Lieder zu zweifeln. "1 Eine solche Argumentation ist abwegig. Daß Forscher unterschiedlicher Meinung über den Inhalt von Texten sind, bedeutet keineswegs, daß diese Texte gefälscht sind. Smits selbst hat dieses Argument wohl für sein Hauptargument gehalten. Das zweite Argument: Die ŪsinšsLieder sind erst zur Zeit der völkischen Erweckungsbewegung erschienen, in früheren Liedersammlungen sind Lieder über Ūsiṇš nicht zu finden. „Dagegen finden wir die echten lettischen Gottheiten, wie Pērkons, Laima, Dēkla, Kärta, Vel̦u mäte u. a. in allen Liedersammlungen und lange vor den Zeiten des Ūsinšs. "2 Auch dieses Argument ist bedeutungslos, denn vor den Üsiņš-Liedern sind Volkslieder nur in sehr beschränktem Umfang gesammelt und publiziert worden ${ }^{3}$. Aber abgesehen davon verliert dieses Argument jede Aussagekraft, wenn wir wissen, daß Stribiňš schon 1606 einen Gott Ūsinšs bezeugt hat. Wie schwach der Grund von Šmits in dieser Hinsicht ist, zeigen die eben zitierten Worte, in denen er mehr unter den echten lettischen Göttern die Pseudogottheit Dēkla, d.i. die hl. Thekla nennt4. Wenn er darauf verweist, daß Ūsiņš in der Folklore spät in Erscheinung tritt, dann wird die Nennung der Kärta noch unverständlicher, die in der lettischen Folklore noch später auftritt ${ }^{5}$.

Der ernsthafteste und unbestreitbare Einwand gegen die Ūsinš-Lieder ist in einzelnen Wörtern und Ausdrücken begründet, die Šmits in seinen Textausgaben hervorhebt und von denen er sagt, daß sie ,durchaus nicht mit den echten Volksliedern übereinstimmen". Seine Einwände sind in diesem Zusammenhang die folgenden: „,Der Inhalt der Ūsinšs-Lieder stimmt mit den echten Volksliedern durchaus nicht überein. In zwei Liedern (23 und 24) fressen die Pferde besser, wenn Mädchen zur nächtlichen Hütung reiten, dagegen klagen in einem anderen Lied (7) die Burschen, daß der Frühling komme und daß sie nun würden zur nächtlichen Hütung reiten müssen. Martin zieht [?!] im Herbst Gerste (3), - Ūsiņš bringt den Pferden 'Zuckerwasser' dim. (7), - die Pferde sind, 'mager aufgefüttert', die Knechte aber 'fett aufgefüttert' (! 20), - die Pferde laufen mit den Pflugscharen (wohl Pflügen, 25) in den Wald, - das Pferd läuft, seinen Schopf (!) bewegend' (28), - den Hahn schlachtet man dem Ūsinšs, damit die Pferde wie ein geschlachteter Hahn tanzen (29). In diesen Liedern prahlen und proze-

1 Šmits 1911, 17.

$2 \mathrm{Ib}$.

s Siehe die Übersicht über das Sammeln der Volkslieder und die darauf bezügliche Literatur Biezais 1961 a, $17 \mathrm{ss}$.

4 Cf. Biezais 1955, $361 \mathrm{ss}$.

5 Ib. 377 ss. Auniņ̌s hat zu den Einwänden von Šmits gesagt, daß in jedem Falle einmal das erste Mal sein muß, wenn eine Entdeckung gemacht oder eine Einsicht gewonnen wird (Auniņ̌s 1913, 22). 
sieren die lettischen Götter (34), sie drohen alle Pferde erfrieren zu lassen (35), schlagen die Menschen mit einem Becher über den Rücken (21), während die Menschen vor Angst vor den Göttern 'schreien' und 'brüllen' (6) und ihnen nach dem Vorbild des Alten Testamentes 'Opfer' bringen (32). Das Wort 'lai' scheint mir sich in der lettischen Sprache nach deutschem Vorbild ausgebreitet zu haben, weswegen es auch in den alten echten Volksliedern verhältnismäßig recht selten anzutreffen ist. In den Usinšs-Liedern erscheint es auf Schritt und Tritt (1, 5, 24, 25, 27, 28, 28 a, 29, 31, 35). Man kann erkennen, daß die Autoren dieser Lieder den Ūsiņš haben schildern wollen und angeben, warum er dieses oder jenes tut, und warum man ihm opfert. Damit entsteht der Eindruck, daß Ūsiņ̌ nicht um der Dichtung willen, erwähnt wird, sondern, daß die Lieder zur Charakterisierung des Úsiņš verfaßt wurden. Alle zu behandelnden Lieder sind in einer einzigen Gemeinde aufgeschrieben worden, es finden sich in ihnen aber Wörter aus unterschiedlichen Mundarten: z. B. Ūsiņš, Ūsenits (4) und Ūss (33), istaba (1) und ustaba (11), uguns (8a [?!] und 10a), guntiņs (8 und 10) und guns (35), akmens (36) und akmins (40a), sēdies (1) und sēsties (11 a). Manchen Phrasen fehlt es sowohl an der Grammatik, als auch an der Logik. So geht Úsiņš z. B. seine Kinder besehen, 'ob die aßen, ob die tranken, ob von Gott die Gesundheit' (26). Ein anderes Beispiel (3) ist: 'Usiņš kommt mit einem Gefilde voll Gras, Martin mit [vollem] Roggenfach'.'1

Diese Beobachtungen von Šmits an den in den Üsinšs-Liedern anzutreffenden Wörtern und Ausdrücken zeigen unmißverständlich, daß die Texte in sehr unvollkommener Sprache aufgeschrieben worden sind, an der der Einfluß später modernisierter Sprache zu erkennen ist. Die Frage aber bleibt offen, ob das geschehen ist, um besondere Texte mit Aussagen über Ūsiņ̌̌ anzufertigen, oder ob sie nur die sprachlichen Fähigkeiten und die Vorstellungen der Sprecher der Lieder widerspiegeln. Bevor wir uns aber über die Ansicht von Smits über diese Texte als gefälschte äußern, muß man hören, was Auniņš zu so schweren Beschuldigungen sagt. Er gibt die Antwort in seiner letzten Schrift, die ein Jahr vor seinem Tode gedruckt wurde.

,,Es verging aber noch eine längere Zeit, und ich hatte schon aufgehört nach dem Uhsin zu fragen, bis ich einmal Gast in dem Kerstenbehmschen

1 Šmits 1911, 18. Die im Zitat genannten Nummern der Dainas verweisen auf die von Auniņš, 1881, gedruckten und numerierten Texte. In dieser Arbeit sind diese Texte mit dem Buchstaben A und den Originalnummern von Aunin̦š nach dem deutschen Text aufgeführt, wenn wir auch seine deutsche Übersetzung übernommen haben; wenn wir nur den lettischen Text übernommen haben, steht $\mathbf{A}$ hinter dem lettischen Text. In den Fällen, wo die Texte von Auniņš als Varianten anderen Texten angefügt wurden, steht das A vor einer solchen Variante. 
[Kārzdaba] Patkul-Gesinde wurde [...]. Das Patkul-Gesinde liegt auf dem Kerstenbehmschen Uhsiņberg, und das veranlaßte mich die Wirtin zu fragen, da sie auf dem Uhsinberg lebe, müsse sie doch auch wissen, was und wer Uhsin sei. Ach, sagte sie, jetzt weiß man nicht mehr viel von dem Uhsin; aber als ich ein Kind war und die Kühe auf die Hütung treiben sollte, da lernten wir verschiedene Uhsing-Lieder singen, die uns die Wirtin lehrte. Das ist sehr interessant, erwiderte ich, und fragte sie weiter, ob sie sich noch einiger solcher Lieder erinnern könnte. Und da wußte sie auf der Stelle ein paar Uhsin-Lieder zu recitieren, die ich sofort niederschrieb. Das war der Anfang meiner Sammlung. Nun fragte ich nicht mehr nur allgemein nach den Uhsin-Opfern etc., sondern nach Uhsing-Liedern, und zwar meist alte Frauen. Ich recitierte solchen alten Frauen irgend einen Tetrastich aus meiner Sammlung und sah, wie die alten Züge sich freudig erhellten; bekam die Antwort: 'jāa, to mēs zinām; tā bērnu gados dziedājām'. [Ja, die kennen wir, die haben wir in Kindheitstagen gesungen.] Nun fragte ich weiter, ob sie noch andere ähnliche Lieder wüßten, in denen des Uhsin erwähnt würde. So wuchs meine Sammlung.

Dann habe ich später wol auch noch ein paar junge Mädchen gebeten, sich in ihren Kreisen nach Uhsin,Liedern zu erkundigen, namentlich bei älteren Frauen, und sie mir zuzustellen. Auf diesem Wege habe ich auch noch einige Lieder erhalten, die nicht von mir selbst unmittelbar aufgeschrieben worden sind. Meine Sammlung hat stattgefunden noch in den siebziger Jahren des vorigen Jahrhunderts. Es ist seitdem ein Menschenalter vergangen. Die Mehrzahl der alten Leute, von denen ich die Uhsin-Lieder erhalten habe, leben jetzt nicht mehr. Es ist im Laufe der letzten 35 Jahre wieder nicht weniges von den alten Ueberlieferungen begraben worden. $\mathrm{Zu}$ meinem Bedauern habe ich die Handschriften derer, die mir schriftlich die von ihnen aufgeschriebenen Uhsing-Lieder zugesandt haben, nicht verwahrt. Als die Lieder gedruckt vorlagen, habe ich die Manuskripte, fremde und eigene, mit dem Material über den Uhsin-Mythus vernichtet. Ich hielt eine Fälschung für ausgeschlossen. Seit Jahren warte ich mit fehr großer Spannung auf den Schlußband der großen Baronschen Sammlung lettischer Volkslieder, der uns die Lieder mythologischen Inhalts bringen soll. Ich hoffte in dieser Sammlung eine Anzahl von Uhsin- und Johannisliedern zu finden. Nach den Mitteilungen des Herrn Professor Schmidt fürchte ich sehr enttäuscht zu werden. Sehr ungünstig für meine Auffassung und Deutung des Uhsing-Mythus lautet das von Prof. Sohmidt angeführte Urteil [...]: 'Pēc Barona tēva domām viņš (proti Ūsiņš) tautas dziesmās nav nodibinājies, bet ir tikai ieviesies vēlākos laikos'. [Nach Meinung von Vater Baron ist er (nämlich Ūsinš) in den Volksliedern nicht begründet, sondern hat sich erst in späteren Zeiten eingestellt.") Bei aller gebührenden 
Hochachtung vor der Wuchtigkeit dieses Urteils glaube ich doch, daß das Problem über die Entstehung und das Alter der Uhsin-Lieder noch einer eingehenden Untersuchung bedarf. Soweit es Dilettanten gestattet sein dürfte, mit den Meistern von Fach zu reden, würde ich es wagen zu behaupten, daß die Uhsiņ-Lieder vielleicht zu den aller ältesten lettischen Volksliedern gehören, die uns überhaupt aus der Urzeit des lettischen Volkes überliefert sind. Freilich nicht in der Form, wie sie mir mitgeteilt worden sind, und vielleicht nicht alle von mir veröffentlichten. Welche Umwandlungen mögen sie im Lauf vieler Generationen erfahren haben? Muß das nicht auch von allen lettischen Volksliedern gesagt werden?

Wenn Prof. Schmidt schreibt: 'liekas, ka arī māeītājs A. pats nav no vienkāršiem ļaudīm dzirdējis itin nevienas Ūsiṇa dziesmas' [es scheint, daß auch der Pastor A. kein einziges Usinšs-Lied von einfachen Leuten gehört hat], dann kann ich darauf antworten, daß meine Quellen fast ausschließlich aus den Kreisen der 'vienkārši l̦audis' (einfachen Leute] stammen bis auf Professor Jurjan und einem Gemeindelehrer. Die allermerkwürdigsten, interessantesten Lieder habe ich von zwei jungen Mädchen erhalten, die nur eine bescheidene Gemeindeschule besucht hatten. Leider bin ich nicht mehr im Stande, es jetzt noch anzugeben, welche Lieder ich selbst unmittelbar gehört und aufgezeichnet habe und welche mir schriftlich von verschiedenen Personen zugestellt worden sind. Ich muß es nochmals wiederholen, daß ich damals an eine mögliche Fälschung absolut nicht gedacht habe. Die Möglichkeit ist ja freilich nicht ausgeschlossen, daß die eine oder andere Person ihrem Gedächtnis mit ihrer Phantasie zu Hilfe gekommen ist. Das kann sich aber nur auf einzelne Einschiebsel beziehen. "1 Diese offene Antwort des Auniņš hinterläßt den zwar subjektiven, aber eben doch den Eindruck, daß er nichts zu verbergen hat, und daß er hier einen vollkommenen Einblick in die Art bietet, auf die die von ihm veröffentlichten Lieder an ihn gelangt sind. Vor allem ist festzustellen, daß Auniņš selbst keinerlei Fälschungen oder Textveränderungen vorzuwerfen sind. Weiter kann man fragen, ob Auniňs unkritisch war und dadurch das Opfer von Textfälschern wurde. Auch das scheint unglaubhaft, denn der gewichtige Hinweis von Smits, derartige Lieder seien im Namen der nationalen Romantik, ,zusammengedichtet" ${ }^{\text {" }}$ worden, als ein gesteigertes Bedürfnis nach alten religiösen Vorstellungen bestanden habe, ist nicht glaubhaft, da Auniņš seine Texte doch vor der Veröffentlichung im Jahre 1881 gesammelt hat. Wenn nun überhaupt nirgends Texte mit Ūsinš abgedruckt und bekannt waren, können die Sprecher nicht von nationalen Motiven bestimmt gewesen sein. Es bleibt die Möglichkeit, daß die Verfasser direkt von Auniņš beeinflußt ihm zur Freude diese Texte verfaßt hätten.

\footnotetext{
1 Auniņš 1913, 19 ss.
} 
Läßt man das hypothetisch zu, kann es doch nur bei einem Sprecher und etlichen Texten zutreffen, nicht aber auf die ganze Gruppe.

Der stichhaltigste Einwand gegen die Anschauung von Simits aber resultiert aus zwei Umständen. Auniņš selbst hat 1870 die Aufforderung von Berkholz, Nachrichten über Ūsiņš mitzuteilen, negativ beantwortet, weil er bei Umfragen in der Gemeinde Dikli festgestellt hatte, daß dieser im Volke unbekannt ist. Nach dem Umzug in die Gemeinde Cesvaine hat er nicht etwa zuerst Ūsiņš-Lieder zu suchen begonnen, wobei er dann das Opfer der von ihm selbst veranlaßten Fälschungsaktion hätte werden können, sondern umgekehrt. Er begegnete in der neuen Gemeinde Ortsnamen, die das Wort Ūsiňš enthielten und einer Zeitbezeichnung, eben dem Üsinštag. Und nur unter dem Eindruck dieser objektiven Tatsachen erwachte sein Interesse an den Traditionen der Folklore. Sollte auch das gesamte von ihm gesammelte Folklorematerial gefälscht sein, ist die Anschauung von Smits allein schon deswegen abzulehnen, weil diese die Umstände nicht zu erklären vermag, die Auniņš veranlaßten, sich für das Folklorematerial dieses Inhaltes zu interessieren. Der zweite Umstand, der zur Ablehnung der Anschauung von Šmits zwingt, ist, daß der Name Ũsiňs schon in der erwähnten Meldung von Stribiņš belegt ist.

Auniņš starb 1914. Bald wurde Vitols Pastor der Gemeinde Cesvaine. Auch er wandte sich von den von Šmits bezweifelten Ūsiņš-Liedern zu. Seine Absicht war, ,der Frage nachzugehen, wieviel Erinnerung an diese Gottheit im Volke noch lebendig ist. In der Gegend tätig, in der Auniņ̌s seinerzeit die Úsiņš-Lieder aufgeschrieben hatte, wollte der feststellen, ob Šmits mit der Meinung recht habe, daß Auniņ̌ Echtes und Gefälschtes nicht habe zu unterscheiden vermocht. "1 $\mathrm{Er}$ wandte ein bestimmtes Prüfungsverfahren an. Das Schema war sehr einfach. Mehrere Lehrer und Schüler des Gymnasiums Cesvaine erhielten die Aufgabe, im Volk vernommene Äußerungen über Ūsinšs aufzuschreiben und zu erfragen, , welche Ūsiņš-Lieder die alten Leute auswendig kennen“. Die dritte Maßnahme bestand darin, die 42 Lieder des Auniņš zu verlesen und zu erfragen, welche davon die befragte Person kennt. Das Ergebnis ist in vielerlei Hinsicht interessant und bezeichnend. Es bietet nicht nur Angaben über das begrenzte Gebiet von Cesvaine und das Ausmaß der Bewahrung von volkskundlichen Überlieferungen darin, sondern über die Tradierung der Dainas überhaupt, was in der lettischen Folklore ein bis jetzt noch völlig unbeachtetes Forschungsfeld ist. Vitols hat mittels seines oben genannten Verfahrens von 13 Personen Auskünfte erhalten. Wir bringen die von ihm gewonnenen Ergebnisse tabellarisch:

1 Vitols 1921, 1209. 


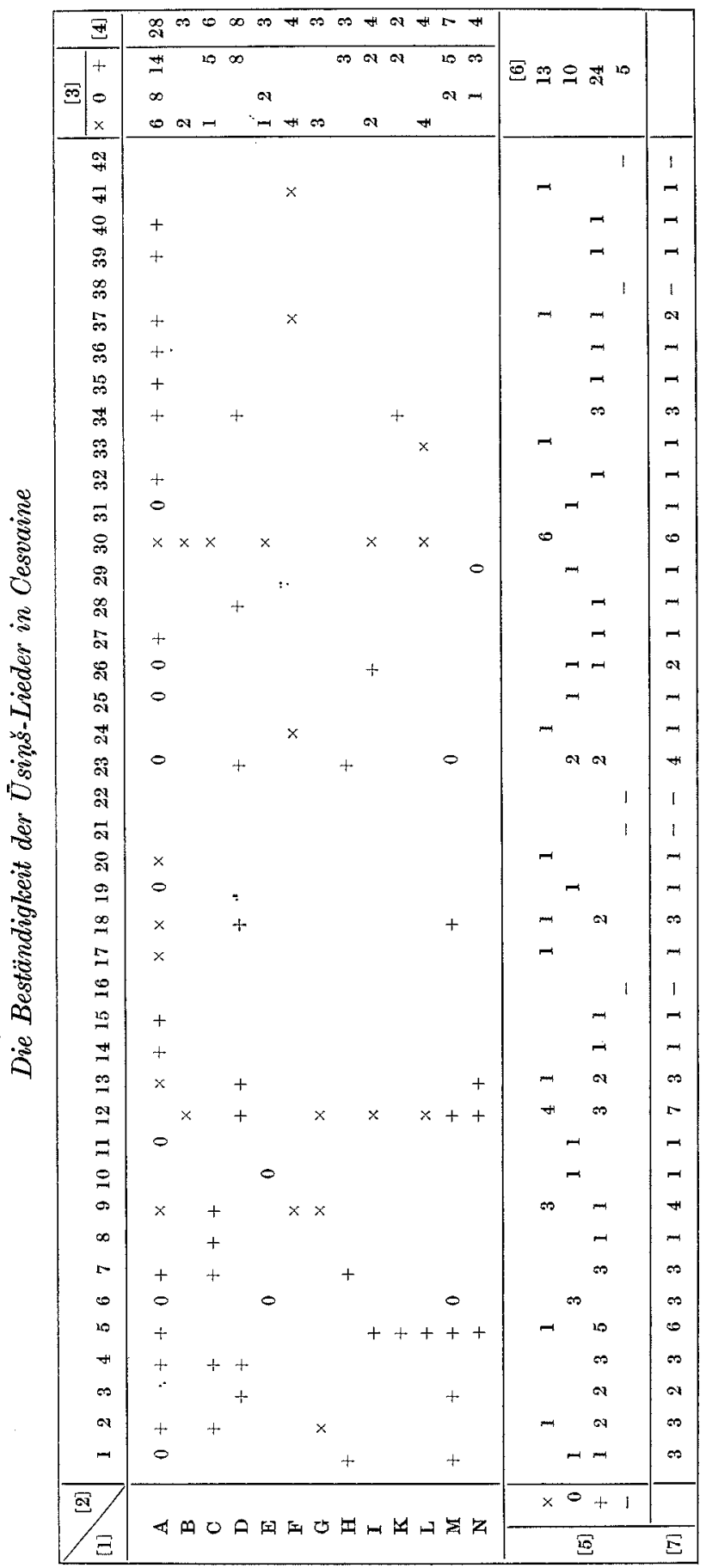

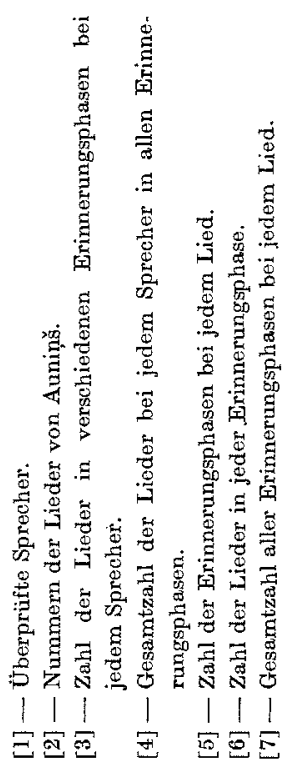

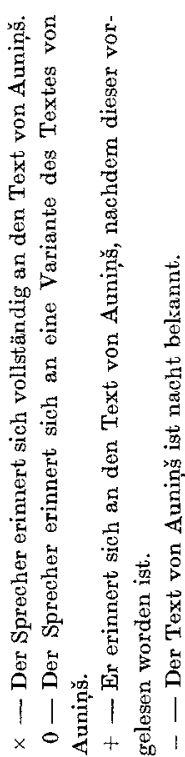


Die Tabelle zeigt, daß zur Zeit der von Vitols veranstalteten Umfrage die Texte 10, 16, 21, 22, 38 und 42 des Auniņš völlig vergessen waren. Dabei ist freilich anzumerken, daß es nicht völlig sicher ist, daß diese Texte je in Cesvaine bekannt gewesen sind, da Aunị̌s ja bekanntlich die Orte der Niederschrift seiner Texte nicht angegeben hat. Dieselbe Unsicherheit besteht auch bei der Umfrage des Vitols, die zwar Lehrer und Schüler des Gymnasiums Cesvaine durchgeführt haben, bei der aber nicht bekannt ist, ob sie im begrenzten Gebiet von Cesvaine erfolgte, denn Lehrer und Schüler dieses Gymnasiums konnten ja auch aus einem größeren Umkreis stammen. Jedenfalls erscheinen diese 6 Texte in der Umfrage des Vitols nicht mehr. Aus der Tabelle wird weiter deutlich, daß sich die Texte in drei Gruppen einteilen lassen, was aus der dreigeteilten Spalte rechts hervorgeht. Das sind Texte, die bei der Umfrage sich als denen von Auniņ̌s identisch erwiesen, also seit 1880 überliefert wurden. Das sind 13 Texte, und sie wurden von 8 Personen gemeldet. Nur in drei Fällen haben mehrere Personen den gleichen Text bewahrt, so 6 Personen den Text 30, 11 Personen den Text 4 und 3 Personen den Text 9. Zu den Texten, die in der aktiven Erinnerung bewahrt wurden, sind auch die zu zählen, die Vìtols als Varianten der Texte von Auniņš bezeichnet, denn es gehört zum Wesen der Wiedergabe von Folklore, daß einzelne Wörter und Vorstellungen sich wandeln können. Wichtig ist, daß die Texte spontane Aussagen sind, und nicht durch irgendwelche Hilfsmittel ins Gedächtnis zurückgerufen wurden. Von Texten, die solchen von Auniņš mit Varianten entsprechen, finden sich 9 , und sie verteilen sich auf 4 Personen, dabei kannten einen von diesen Texten 3 Personen und einen zweiten 2 Personen. Alle diese Varianten hat Vitols in seiner Arbeit veröffentlicht1. Unmißverständlich geht aus dem Gesagten hervor, daß 22 der von Aunin̦š abgedruckten Lieder um 1920 noch bekannt waren.

Vitols ist noch weiter gegangen. Er hatte ja, wie gesagt, noch einen dritten Schritt vorgesehen, nämlich die Aunịšs-Texte vorzulesen und dabei festzustellen, wie weit diese eine Erinnerung an einmal gekannte und dann vergessene Texte erwecken. Die Tabelle zeigt, daß 8 von seinen $13 \mathrm{Ge}$ währsleuten sich auf diese Weise erinnerten, bzw. erklärten, daß die verlesenen Texte ihnen bekannt seien. In dieser Art waren insgesamt 24 Lieder bekannt. Uns interessiert in diesem Zusammenhang, ob die auf diese Weise ins Gedächtnis zurückgerufenen Lieder das Bild ergänzen, daß er durch die zwei ersten Gruppen erhalten hatte. In dieser Hinsicht war das Ergebnis überraschend. Die befragten Personen erklärten, wie aus der Tabelle ersichtlich, 14 weitere Texte als bekannt, die in der aktiven Erinnerung fehlten. Vitols folgert, daß 36 von den Auniņš-Texten noch im Bewußtsein der Leute waren. Insgesamt hat Vitols in diesen drei Gruppen 77 Texte ver-

${ }^{1} \mathrm{Ib} .1209 \mathrm{~s}$. 
wendet. Es muß festgehalten werden, daß Vitols bei der seiner Gewährsträgerinnen, die die größte Anzahl von Texten geliefert hatte 6 richtige Auniņš-Texte, 8 von deren Varianten, 14 nach Verlesen wiedererkannte), nämlich 28 von insgesamt 77, anmerkt, daß deren Mutter ihrerzeit „dem Auniņšs viele Ūsiņš-Lieder zugetragen hat". Bei der Gewährsträgerin I vermerkt Vitols: ,,Die Mutter der Sprecherin hat Auniņš mit den UsiņšLiederm bekannt gemacht, deren Mutter aber habe 3 Tage mit dem Sagen derselben bei ihm zugebracht. ${ }^{{ }_{1} 1}$ DaB die Namen der Personen in die Arbeit von Vitols fehlen, ist ein Mangel. Es gibt noch mehr, auf die hat schon Smits, wie wir später sehen werden, hingewiesen.

Was sind nun Folgerungen Vìtols'? Er weist den Gedanken zurück, Auniṇš habe die Lieder gefälscht. Dann verbleibt die Möglichkeit, „Auniṇš habe die von anderen gefälschten Lieder für echt gehalten". Ein Vorwurf, den zweifelsohne Endzelins und Smits schon seit 1903 ausgesprochen hatten. Gegenüber dem letzteren verweist er darauf, daß es nicht möglich sei, wegen des Erscheinens, ,vieler modermer Begriffe" allein die Lieder abzulehnen. Zu den Hinweisen der genannten Forscher über Mängel in Rhythmus und Form bei diesen Liedern bemerkt Vitols: „,Hier darf nicht ïbersehen werden, daß die Ūsinšs-Lieder ein anderes Geschick haben, als die sonstigen. Es scheint, als seien diese ursprünglich nur den Männern bekannt gewesen, die ja formal ungeschickter als Frauen sind. Klingt nicht aus den Liedern Aun. 4 und 37 burschenmäBige Bravour? Ebenso wird auch Aun. 38 nur aus Männermund geklungen haben. Schließlich sind schon mehr als 40 Jahre vergangen seit Auninšs seine Sammlung veröffentlicht hat. Wären nicht sehr ungeschickte und direkte Fälschungen in so langer Zeit völlig vergessen worden?" 2

Gewiß hat sich Vitols mit dem letzten Satz geirrt, was erklärlich ist, da ihm tieferer Einblick in die Folkloreforschung fehlt. Aber an der guten Absicht, in den Grenzen seiner Möglichkeiten die Validität der von Auniṇš publizierten Texte zu klären, darf bei Vitols nicht gezweifelt werden. Es ist zuzugeben, daß die Texte das Fortbestehen der Ūinšs-Lieder bezeugen. Man geht wohl nicht fehl, wenn man annimmt, die Schrift von Vitols sei eine Reaktion auf die Aroganz, mit der Endzelīns und Smits sich gegen Auniņš gewandt haben. Die Diskussion war aber damit nicht beendet.

Diese wohlgemeinte Forschung des Vitols hat Smits mehrfach mißverstanden. Vor allem hat er das Verfahren von Vitols nicht verstanden und gemeint, dieser habe die Texte von Auniņš überprüf, indem er sie

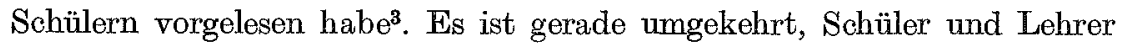

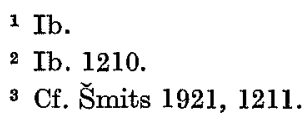


haben die Texte, wie Vitols dem Smits nochmals erläutert, den Gewährsleuten, ,betagten einfachen Leuten“ vorgelesen, „die alles andere als das Magazin der Latviešu Draugu Biedrība lesen ${ }^{\star 1}$. Das war, wie schon gesagt, ein legitimes Forschungsverfahren.

Ebenso irrtümlich ist der Einwand von Smits, daß ,die Sammler der Angaben fast stets dieselben wenigen Personen sind und in jüngster Zeit auch schon deren Kinder und Kindeskinder". Hier hat Smits die Sammler mit den Gewährsleuten verwechselt. Mit anderen Worten, Smits gefällt es nicht, daß die Gewährsleute über mehrere Generationen derselben Familie angehören. Dieser sein Einwand aber hängt in der Luft, denn er nennt keinen weiteren, als die zwei Fälle, die Vittols selbst vermerkt, und die oben erwähnt wurden. Das zeigt nichts anderes, als daß Vitols offen die Umstände aufgezeigt hat, die für die Tradierung und das Verständnis von Texten Bedeutung haben können. Er setzt damit die schon von Auniņ̌s geübte Offenheit fort. Als Auniňš 1905 die Echtheit seiner Texte verteidigt, hatte er in dem oben gebrachten Zitat die Worte geschrieben: ,Wie oft bekommt man auf die Frage: 'aber was bedeutet das?' die Antwort: 'Das wissen wir nicht, so hat uns schon die Wirtin singen gelehrt, als wir Hütemädchen waren'." Smits benutzt jetzt diese Worte von Auniņš gegen Vitols und ruft aus: „So hat denn wenigstens eine Wirtin diese Lieder gelehrt."3 $\mathrm{Zu}$ diesen Worten von Smits werden wir in Kürze zurückkehren.

Das gleiche Mißverständnis besteht bei der Aussage des Vītols, daß $\mathrm{B}$ die Úsiņš-Lieder unterschiedliche Schicksale hatten. Smits deutet sie offenbar so, daß deswegen die Lieder geringere Glaubwürdigkeit hätten. Vïtols versucht, ganz im Gegenteil, die Unebenheiten im Rhythmus und andere Mängel dadurch zu erklären, daB die Lieder ein , anderes Schicksal“ gehabt haben, es seien nämlich Männerlieder, und Männer seien in der Dichtkunst weniger gewandt. Die Deutung der Worte von Vitols durch Smits ist unbegründet.

Dagegen ist der Forderung von Smits, die schon bei den Texten von Auniņš angemeldet wurde, daß nämlich Namen und andere Angaben der Sprecher zu nennen seien, beizupflichten. Das hat leider auch Vitols nicht gemacht. Und das wird umso weniger verständlich, da er doch die ganze Diskussion um die Texte des Auniņš und die Forderung auf Bekanntgabe der Autentizität der Sprecher kannte. Daß sich Vitols der Schwierigkeit bewußt war, zeigt seine Rechtfertigung dafür, daB er die Namen nicht beigefügt hat, weil ,er nicht von allen die Erlaubnis bekommen habe“" Das erscheint erstaunlich. Nach den Einwänden von Smits hat Vitols

1 Vitols 1921 a, 1325.

2 Cf. oben S. 42.

3 Šmits 1921, 1212. 
gesagt, er habe die Namen der Sprecher der Redaktion der Zeitschrift, die seine Schrift veröffentlichte, mitgeteilt1. Ebenso unverständlich ist aber auch die Reaktion von Śmits auf diese Mitteilung: ,[...] ich habe durchaus nicht den Wunsch, alle Erzähler der Traditionen zu erfahren, und ihnen womöglich Unannehmlichkeiten zu bereiten." Tatsächlich aber bestand die Forderung von Šmits darin, die Namen der Gewährsleute zu erfahren! Noch weniger verständlich ist, was er mit den Worten vom Bereiten von Unannehmlichkeiten meint. Damit schließt die fast 20-jährige Diskussion über die von Auniņš gesammelten und veröffentlichten Üsinšs-Lieder. Was sind nun die Ergebnisse dieser Diskussion? Vor allem die von Endzelins zuerst erhobene und dann von Smits bekräftigte Forderung, die Texte der Ūsiņš-Lieder seien nur auszuwerten, wenn es genaue Angaben über deren Aufzeichnung gibt. Solche fehlen bei Auniņš und auch bei Vitols. Das ist ein Mangel, der diese Liedergruppe auch weiterhin begleitet und nur zum Teil behoben ist. Andererseits mußte auch die schonungsloseste Kritik zugeben, daß ,,mehr als die Hälfte dieser Liederchen echt sein könnten, wenn einzelne Ausdrücke darin versehentlich verdorben worden wären “3. Dies ist als der größte Gewinn dieser Diskussion anzusehen.

Die Diskussion deckte auch einen wesenhaften Mangel bei der Bewertung von Folklorematerial in jener Zeit auf. Es bestünde kein AnlaB, sich damit zu befassen, wenn die irrtümlichen Anschauungen jener Zeit nicht zu einer Art Dogma für das Verständnis und die Auswertung der Dainas geworden wäre. Immer wieder klingt neben der begründeten Forderung auch eine negative Einstellung an. Diese ist am deutlichsten mit den oben erwähnten Worten von Smits ausgedrückt. Eine Sprecherin bekennt, daß sie den Sinn des Inhalts nicht kennt, daß aber die Wirtin sie gelehrt habe, als sie Hütemädchen war. Smits erregt sich darüber, daß ein ,Lehren" stattgefunden habe. Diese seine Einstellung kennzeichnet seine Position. Sie zeigt, daß er statt an das „Lehren" an spontane Schöpfung denkt. Danach müßte die völkstümliche Tradition in jedem Individuum in schöpferischen Augenblicken neu geboren werden. Das Individuum gäbe damit mit seiner Schöpfung nur die in einem Kollektiv, in diesem Falle im Volke, bewahrten Vorstellungen, Ideen usw. wieder ${ }^{4}$. Das ist die bekannte Nationalromantik. Hierin ist Smits Kind seiner Zeit, der seine Erkenntnisse direkt unter dem Einfluß Naumanns ausspricht. Dies ist eine der Illusionen, die Šmits in seiner Polemik gegen Auniņš und Vìtols leiteten. Wir wissen heute, daß

1 Vitols $1921 \mathrm{a}, 1325$.

2 Smits $1921 a, 1326$.

3 Šmits 1921, 1211.

4 Darüber habe ich mich, 1955, 63 ss, eingehender geäußert. Cf. auch Rooth, Anna Birgitta $14 \mathrm{~s}$. 
völkische Traditionen von individuellen Traditionsträgern tradiert werden, und daß sie daraus leben. In diesem Sinne sind die zwei von Vitols erwähnten Fälle, die über die Enkelin erzählen, welche weiß, daß Mutter und Großmutter dem Auniņš Angaben über Ūsiņš gemacht haben, Zeugnisse echter Überlieferung von Vollksgut. Dasselbe gilt für die von Śmits abgelehnte Tatsache, wonach eine Wirtin ihr Hütemädchen Lieder, darunter auch die Ūsiņš-Lieder gelehrt hat. Gerade eine solche Art der Überlieferung von Liedern an die nächste Generation, die oft, wie in diesem Falle, deren ursprüngliche Bedeutung nicht mehr versteht, ist eine Bestätigung dafür, daß es sich hier um echte völkische Tradition handelt.

In dieser Diskussion trifft man häufig auf Ausdrücke wie ,,echtes Volkslied" und „unechtes Volkslied“. In dieser Diskussion steht die Frage nach der Echtheit oder Unechtheit der Ūsinš-Lieder in Wahrheit im Mittelpunkt. Am klarsten wird das durch die Worte von Smits ausgedrückt: „Unter diesen Liedern sind einige ganz sichere, über die niemand Zweifel geäußert hat. Andere hingegen sind allgemein als unechte erkannt und sogar R. Aunings übernimmt keine Verantwortung für alle Lieder." 1 Hier können wir die in der Schärfe und Hitze der Polemik ausgesprochenen eindeutig unwahren Worte beiseite lassen, Auniņ̌s hätte die Verantwortung für alle seine Texte nicht übernommen. Ganz im Gegenteil hat er offen und fest und dazu wiederholt unterstrichen, daß er alle Texte so dargeboten habe, wie er sie von Sprechern gehört hat ${ }^{2}$. Smits hat auch nicht konkret angegeben, was er unter den Worten ,allgemein als unechte anerkannt" versteht. Jedenfalls ist nirgends in den Schriften eine „Allgemeinheit" in diesem negativen Sinne dokumentiert. Es ist allein Smits, der eine solche Ansicht verkündet, und allenfalls Endzelinns bezüglich des Textes 38 bei Auniņš. Insofern ist auch diese Berufung auf die Allgemeinheit aus der polemischen Situation zu erklären. Bisweilen benutzt Smits neben ,echten“ und ,,unechten" Volksliedern auch Synonyme zum Ausdrücken des gleichen Sachverhalts, etwa wenn er von ,alten und unveränderten“ Liedern spricht. Er denkt auch an die Möglichkeit, die Lieder in ,unveränderter Form zu rekonstruieren “3. Mit diesen letzten Aussprüchen ist Šmits an ein prinzipielles und wichtiges Problem geraten. Um bestimmen zu können, was ein echtes und was ein unechtes Volkslied ist, sind unbedingt Kriterien aufzustellen, die eine diesbezügliche Klassifizierung dieser Lieder bestimmen. Hier steht nun nicht nur Smits, sondern jeder Volkskundler vor einem

1 Šmits 1921, 1211. Ähnlich Śmits 1921a, 1326: ,,Ich bleibe bei meiner Überzeugung, daß ein großer Teil der Üsiṇš-Lieder keine alten und unveränderten Lieder sein kann. “

2 Cf. die Worte von Auniņš oben S. 42.

3 Cf. S̆mits 1921a, 1326. 
Problem ${ }^{1}$. Bekanntlich hat Smits, ebensowenig wie Endzelīns eine Definition des Volksliedes geliefert. Statt dessen aber haben sie wohl einige praktische Kriterien genannt. Endzelins sagt, daß ihm 38. Text, ,anstößig“c ist und zwar aus zwei Gründen, nämlich ,, bezüglich des Rhythmus, wie des Inhalts". Da er nicht Konkretes nennt, welchen Fehler der Rhythmus hat, und welche Züge des Inhalts ihm verdächtig erscheinen, ist keine Diskussion möglich. Das ist aus seiner schon erwähnten autoritativen Einstellung zu erklären.

Bei den Einwänden von Šmits ist die Lage ein wenig besser. Eines seiner Argumente zum Nachweis der sogenannten unechten Lieder ist auch die Rhythmusfrage. Er sagt, ebensowenig wie Endzelins, mit klaren Worten, welchen rhythmischen Mangel die Lieder von Auniņš aufweisen. Man kann aber mit Sicherheit erraten, was beide Autoren unter richtigem Rhythmus verstehen. Das Problem des Rhythmus der Dainas ist wiederholt untersucht worden, und es besteht hier eine fest begründete Tradition. Diese Lieder sind im trochäischen oder daktylischen Versmaß verfaßt2. In dieser Hinsicht weisen die Auninšs-Lieder große Unebenheiten auf. In vielen Texten ist der Rhythmus fehlerhaft, oder es fehlt überhaupt daran. Die Frage nach dem Rhythmus ist jedoch nicht so einfach, und dessen Fehler in den Texten von Auniņš als Argument gegen ihre Echtheit heranzuziehen, ist in Wahrheit nicht möglich. Smits hatte ein ideales Versmaß der Dainas vor Augen, das auch in vielen Texten der großen Sammlung LD bezeugt ist. In der Zeit, als Smits seine Einwände formulierte, hatte sich allmählich mit der Veröffentlichung der LD die Auffassung vom genannten Versmaß als Norm durchgesetzt. Hier ist es wichtig daran zu erinnern, wie diese normative Auffassung entstanden war. Und man muß sich dem Ordner und Herausgeber der LD zuwenden. Es ist hier nicht der

1 Schon ein oberflächlicher Einblick in die Arbeiten skandinavischer Folkloreforscher läßt erkennen, daß über den Begriff des Volksliedes keine Klarheit besteht. Svensson schrieb eine Einführung in das Studium der Volkskunde, in der sich auch ein Kapitel über Volkslieder vorhanden ist (152), hat aber keine Definition des Volksliedes gegeben. Auch seine Schülerin Anna Birgitta Rooth (1965) hat in einer ähnlichen Arbeit eine solche nicht gegeben, obwohl sie sich über Volksdichtung verbreitet. Man hätte eine solche nun in einer Spezialarbeit mit hohen wissenschaftlichen Ambitionen von skandinavischen Spezialisten, NK 9 A: Folkvisor, erwarten können. Aber auch dort finden wir sie nicht. Daß auch hier große Unklarheiten herrschen, zeigt sich besonders deutlich in einer Schrift von Bødker über das Volkslied mit dem Untertitel: Ein Beitrag zur Verbiestering der Terminologie (cf. Bødker 273). Wenn noch heute Wissenschaftler sich mit diesem Problem befassen, können wir Smits am Anfang dieses Jhs. besser verstehen.

a Dieses Problem ist von Bērziņš kompetent exörtert worden und dabei schon sehr früh. Es scheint, als ob Endzelīns und S̆mits ihre Ansichten auf die Arbeit Bērziņš, 1894 s, stützen. Als Hauptarbeit in diesen Fragen ist Bërzinšs, 1959, anzusehen. 
Ort, die Redaktion und die damit verbundene Problematik der LD Ausgabe zu erörtern. Es ist aber notwendig, darauf hinzuweisen, daß die in die LD aufgenommenen Texte weder so aufgeschrieben noch so abgedruckt wurden, wie sie im Volke gehört worden waren. Vor allem haben die Aufzeichner sie in die damals gültige Schriftsprache übertragen'. Danach hat der Herausgeber Barons sie seinerseits so verändert, daß sie einem von ihm angenommenen Grundtext entsprachen, den er aus den vielen ihm zugänglichen Varianten zu rekonstruieren sich bemühte ${ }^{2}$. Und dabei hat der Herausgeber, gerade des Rhythmus wegen viele Texte verändert: „Um des Rhythmus willen wurden fehlende Wörter in die Zeilen hineingeschrieben und überhaupt die nicht am Platze befindlichen Deminutive ausgemerzt. "33 Die Absicht der Aufzeichner dieser Texte und des Herausgebers war es, einen Grundtext zu rekonstruieren, d. h. den ,echten“ Text zu finden, der dann verändert worden wäre.

Durch diese Maßnahmen ist die objektive Forschung in zweierlei Hinsicht behindert. Erstens sind die im Volke gehörten Texte nicht so aufgeschrieben, wie sie gesagt wurden, mit anderen Worten der wahre Grundtext oder Urtext ist gar nicht bekannt. Zweitens wurde durch die Veröffentlichung derart bearbeiteter und veränderter Texte die Anschauung vom idealen Text mit dem richtigen Versmaß begründet, den es in vielen Fällen empirisch niemals gegeben hat $t^{4}$. Damit wird deutlich, daß das von Smits gegen Auniņš angeführte Argument vom richtigen Rhythmus nicht ausreicht, um die, wie Smits sagt, ,Echtheit" der Auniņš-Texte anzuzweifeln. Wie wir schon zuvor gelesen haben, bekundet Auniņš wiederholt und mit besonderem Nachdruck, daß er die Texte im Jahre 1881 genau so veröffentlicht hat,

1 Darüber hat sich Endzelīns, 1904, 553 ss, bei der Besprechung des 2. Bandes der Dainas verbreitet. Cf. auch Bērziñ 1893,28 ss und Ozols 1962, 39.

2 So Aräjs 1959, 308: „In den Grundliedern sind mehrere Lieder verschmelzt, ohne die unterschiedlichen Formen zu zeigen, Wörter auszuwechseln usw." Er bringt dort auch einige Beispiele. Arājs schließt seine Erkenntnisse mit der Behauptung ab: ,,[...] das Bearbeitungsverfahren der Texte, auch wenn der Redakteur dabei im Volke ent. standene Texte benutzt und sich vor eigenwilliger literarischer Behandlung hütet, führt dazu, daß aus dem Gedruckten nicht mehr eine vollständige Vorstellung über die eingesandten Volksliedertexte zu entnehmen ist, sondern zeigt diese als eine unterschiedliche, wenn im Grunde auch aus Elementen echter Lieder bestehende Kombination" (ib. 310). Arājs meint, daß diese Umdichtung ,so weit gehen kann, daß man beim Vergleich des Gedruckten und des Originals von qualitativ unterschiedlichen Texten sprechen muß" (ib. 313).

s Ib. 314; ef. auch id. 1962, 22.

4 Auf derartige Textveränderungen beziehen sich auch die scharfen Worte von Endzelīns über Lehrer, die von den Schülern gesammelte Texte korrigiert haben: „Denn der Lehrer hat den Aufschreiber nicht rechtzeitig darüber befragt, wie die Stelle genau zu lesen ist. Später korrigiert er nach seinem Dafürhalten den Fehler, ein solcher Text ist dann aber kein echter Volksliedtext mehr" (Endzelīns 1904, 554). 
wie sie ihm zugeschickt wurden. Die Unebenheiten des Rhythmus sind geradezu ein Beweis dafür, daß die Texte unverändert aufgeschrieben wurden, und darin hat Auniņš recht. Šmits hat sich hier von einer illusorischen Vorstellung vom idealen Volkslied mit richtigem Versmaß leiten lassen, die sich als normativer Begriff im Ergebnis der von Barons veröffentlichten Dainas gebildet hatte.

Das andere Kriterium ist der von Endzelins erwähnte ,anstößige“ Inhalt. Wie schon gesagt, ist eine Diskussion mit ihm nicht möglich, weil er nicht sagt, was er unter, ,anstößig“ versteht. Seine Besprechung des 2. Bandes der LD vermittelt ein wenig Einblick in die Anschauungen von Endzelins in dieser Sache ${ }^{1}$. Smits freilich hat versucht, diesen unklaren Begriff zu bestimmen. Er lehnt derartige Texte aus lexikalischen Gründen ab. Wenn in Texten neuere Wortbildungen auftreten, lehnt er sie ab, wie er das besonders in der Diskussion mit Vitols erklärt. Ein solches Beispiel ist für ihn das im 17. Liede vorkommende cukur üdentin̨ 'Zuckerwasser' dim., weil früher statt cukurs - sukurs gesprochen worden $\operatorname{sei}^{2}$. Diese seine Behauptung ist an sich richtig. Die Frage ist aber doch eine völlig andere ob das Eindringen neuerer Wortformen in einen Text bedeutet, daB die im Text ausgedrückten Begriffe oder Ideen neu sind, und mehr noch, daß dann der Text nicht ,echt" sei? Vitols antwortet sofort und weist die Anschauung von Šmits zurück. Er sagt: ,,Ich nenne dieses Beispiel [mit dem Zuckerwasser] nur mit der Absicht, zu zeigen, daß man sich nicht vor jedem modernen Begriff in den Volksliedern zu fürchten braucht. Man kann hier doch nicht von 'einer absichtlichen Änderung' sprechen. [...] Das ist Volkstradition und keine 'absichtliche Fälschung'. "3 Šmits hatte zwar richtig erkannt, daß das Auftreten neuer Begriffe und lexikalischer Benennungen in der Volksüberlieferung ein Zeichen dafür sind, daß die Texte aus neuerer Zeit sind. Darunter können auch bewußte individuelle Gestaltungen sein, die Śmits als Fälschungen bezeichnet. Das bedeutet aber keineswegs, daß das Auftreten solcher neuen Wörter und Begriffe schon beweist, daß die Texte nicht ,echt" sind. Der Fehler ist hier die Verallgemeinerung. Das Merkwürdigste ist, daß Barons schon zu Beginn seiner Veröffentlichungsarbeit an den Dainas am Ende des vorigen Jhs., sich nicht nur dessen bewußt gewesen ist, sondern auch seine Ansicht klar ausgedrückt hat, daß nämlich die völkstümliche Tradition sich in einem ProzeB ununterbrochenen Werdens und Wandelns befindet. So schreibt er ganz zu Beginn seiner Herausgebertätigkeit in einem Brief an Kiparts: ,Wer unsere Volkslieder kennengelernt hat, wird nicht abstreiten, daß sie,

1 Cf. ib. 553 ss.

2 Cf. Šmits 1921, 1212.

3 Vitols 1921 a, 1326. 
zum mindesten deren größter Teil, Gewächs uralter Zeiten sind. Daraus dürfen wir aber nicht schließen, daß sie seit jener Zeit in völliger Erstarrung versteinert sind. Wenn das Volk sie bei Gelegenheiten des Lebensablaufs sang (und das geschieht manchmal, wenn auch in geringem Ausmaß, bis zum heutigen Tage), wurden sie den inzwischen veränderten Umständen und dem Zeitenwechsel sowohl in der Sprache, wie im Inhalt angepaßt. Das ist bei den 'Neckliedern' besonders deutlich. Bei der Neckerei konnte man etwas Neues entdecken, z. B. in der Kleidung, meinethalben gewichste Stiefelchen, eine Brille vor den Augen u. a. Das alles wurde in die älteren Lieder eingeflochten, selten wurden nach dem Muster alter neue Verschen erdacht. Das aber tat nicht irgendein besonderer Dichter, sondern die Sängerinnen selbst im notwendigen Augenblick. Auf diese Weise sind manche Fremdwörter in unsere Lieder gekommen."1 Dieser Text bietet eine prinzipiell richtige Beschreibung des Entstehungs- und Tradierungsvorgangs volkstümlicher Traditionen. Die darin angeführten Beispiele von den gewichsten Stiefeln und der Brille entsprechen genau dem von Šmits kritisierten Zuckerwasser. Insofern sind weder der ,anstößige" Inhalt noch die modernen oder fremden. Wörter an sich ein Grund zum Bezweifeln der Echtheit der völkstümlichen. Traditionen. Das bedeutet, daß die Einwände von Šmits gegen die Auniņš-Texte in dieser Hinsicht unbegründet sind.

Es wäre aber ebenso leichtsinnig anzunehmen, die Einwände und kritischen Bemerkungen seien ohne Bedeutung, als gäbe es unter den Dainas überhaupt keine verkrüppelten Texte, oder als gäbe es darunter tatsächlich keine absichtlichen individuellen Dichtungen, die als dem Volke zuzuschreiben angegeben werden, also Fälschungen.

Solche gibt es tatsächlich, nur sind Verfahren und Kriterien für deren. Feststellung nicht ausreichend, wie Šmits das annahm. An Stelle seiner Methode muß man beachten, was Endzelïns unter Berufung auf Bērziṇš sagt, nämlich, daß es gar nicht möglich sei, in allen Fällen die Fälschung festzustellen, wenn sie geschickt gemacht wurde ${ }^{2}$. Hier ist auch an die ironische Äußerung von Auninš̌ zu erinnern, daß auch unter Eid Gesagtes nicht immer wahr ist. Endzelins beginnt nun das, was wir heute Kontext-

1 Das Zitat ist von Aräjs, 1959, 311, übernommen, und ich habe es nicht überprüfen können, weil die Arbeit, aus der es stammt, im Fond der Akademie der Wissenschaften Lettlands aufbewahrt wird. Diesen Gesichtspunkt von Barons betonen die heutigen Volkskundler Lettlands besonders gern als Beweis dafür, daß die Anschauungen von Barons progressiv waren, so insbesondere Ozols 1962, 38 s and Arājs 1959, 303.

2 Cf. Endzelins 1904, 554. In derselben Schrift ist vermerkt, daß der bedeutende Forscher Bërziņš in seiner Jugend gesammelt und in gutem Glauben die Texte verbessert hat, d. h. sie ,gefälscht" hat, um die Terminologie von Šmits zu benutzen. 
analyse und die ökologische kulturelle Situation nennen ${ }^{1}$. Das bedeutet praktisch die Überprüfung und Bewertung jedes einzelnen Textes und das Aufzeigen der Motive, aus denen sein Inhalt angezweifelt werden kann. Diese Diskussion zeigte, daß große Vorsicht und kritische Überprüfung in jedem einzelnen Fall erforderlich sind, will man die Dainas bei wissenschaftlichen Untersuchungen verwenden. Der größte Gewinn aber war der, daß nun kein Zweifel mehr möglich war daran, daß die Texte des Auniňš, gerade in ihrer derzeitigen Form zeigen, daß sie Angehörige der lebendigen völkischen Tradition sind. Als positives Ergebnis ist auch die Einsicht zu werten, daß es jeder Grundlage entbehrt, in verallgemeinerndem Sinne von echten und von unechten Volksliedern zu sprechen, als wäre es möglich, irgendwelche verbindlichen normativen Kriterien aufzuzeigen. Darüber hinaus mußte man auch auf die nationalromantische Überzeugung von den klassischen genuinen Volksliedern, die später verdorben worden wären, verzichten. Diese Diskussion gab aber auch Veranlassung zu einem negativen und wahrscheinlich auch unwiederbringlichen Ereignis. Da die Diskussion zwischen Auniņ zeitraum der Veröffentlichung der LD vor sich ging, wurden in $L D$, die von Auniňš gesammelten Lieder nicht aufgenommen, was $\mathrm{zu}$ bedauern ist ${ }^{2}$. Das bedeutet gleichzeitig, daß die von Auniņš veröffentlichten Texte weiterhin das folkloristische Hauptmaterial für die Lösung unserer Frage bleibt.

Die Inhaltsanalyse dieser Lieder wird weiter unten vorge nommen werden, deshalb treten wir hier nur noch der Frage näher, ob und in welcher Weise das Material von Auniņš unsere aus dem oben behandelten Quellen gewonnenen Erkenntnisse über den Namen $\bar{U} \operatorname{sinğ~ergänzt.~Dabei~erweist~sich,~}$ daß seine Lieder zu den schon bekannten Namensformen noch die folgenden hinzufügen: $\bar{U} s e n \bar{t} s(4), \bar{U} s a$, Nom. $\bar{U} s s$ (33). Über die erste hat sich schon Endzelīns geäußert und die Form $\bar{U}$ senis neben $\bar{U}$ siņ̌s als Grundform anerkannt ${ }^{3}$, obwohl sie nur einmal in Deminutivform auftritt. Unabhängig

1 Hier ist nochmals an das von Barons Gesagte zu erinnern: ,Sollte es wirklich einige solche geben, so underscheiden sie sich weder im Ausdruck und in der Form, noch im Inhalt von den alten Volksliedern, und da nahezu jedes solche Volkslied Teil eines alten Volksliedes ist, ist auch das 'gefälschte' Volkslied ein Volkslied, nur ein neueres, und das, was in diesen Liedern nicht dem allgemeinen, echten Volksliedgeist (wörtlich 'Mund') widerspricht, kann man zu den Volksliedern zählen, und viele von ihnen habe ich auch in die Dainas aufgenommen" (Arājs 1962, 22).

2 Arājs hält es für ein besonderes Verdienst, daß Barons einen Teil der mythologischen Lieder nicht veröffentlicht hat $(1962,24)$. Das aber bedeutet ein Mißverstehen der Aufgabe eines Herausgebers. Die Bewertung und Verwendung dieser Lieder ist den Forschern zu überlassen, nicht dem Herausgeber der Dainas.

3 Cf. Endzeling 1908, 135. 
davon, was Erklärung und Herkunft dieser Form sein mögen, spricht der Text selbst seine klare Sprache:

4. Usenüts ar Mijeli Kopā divi runājās. $\bar{U} \sin s{ }^{\circ}$ sak' uz Mikeli Trūkums, brāli, räd̄̄j $\bar{a} s$.

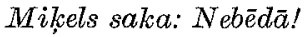
Es tev büšsu palüdzēt; Došu rudzus, došu miežus, Došu labus kumeliñus.
Ũsenits und Michael

Unterhielten sich beide mit einander.

Ũsinš sagte zum Michael:

Bruder, Mangel ist eingetreten.

Michael sagt: Sorge nicht!

Ich werde dir helfen;

Ich werde Roggen geben, ich werde Gerste geben,

Ich werde gute Rößlein geben. A4

Die 3. Zeile dieses Textes zeigt, daß $\bar{U}$ senĩts mit $\bar{U}$ sin̨š identisch ist'1.

Der andere Name $\bar{U} s a$ ist als Genitiv im Text $33 \mathrm{zu}$ finden:

33. Danco $\bar{U}$ sa stilinğ $\bar{\imath}$ Abolaini kumelini, Cierē paši jājōējin?, Zelta pieši kājinna.
Es tanzen im Pferdestand des Stalles von Üsa.

Geäpfelte Rößlein;

Die Reiter dim. selbstspazieren umher Goldene Sporen am Fuß dim. A36

1: Ūsiñ̌s; 2: Mit Hufeisen beschlagenen.

a. A 43: 1:
Storé.

Auch diese Form ist in der ganzen Gruppe der Ūsingš-Lieder nur einmal zu finden. Formal ist sie eine rekonstruierte Grundform des Deminutivs $\bar{U}$ siņš. Sie hat keinen Einfluß auf den Inhalt des Textes. Es ist bezeichnend, daß auch Auniņš in Übereinstimmung mit den anderen Texten sie in deminutiver Form übersetzt, obwohl dafür im lettischen Text selbst kein Grund besteht². Man kann also sagen, daß das von Auniņš gebotene Material zu der Erkenntnis, wonach die Grundform $\bar{U}$ siņš lautet, nichts Neues beiträgt.

2.4.1.2. Neuere Texte.

2.4.1.2.1. Eine geringe Anzahl neuer Dainas bietet Volteris. Noch bevor die Polemik von Endzelins und Šmits mit Auniņš begonnen hatte, veröffentlicht er 189015 Texte mit $3 \mathrm{~V}^{3}$. Diese Texte sind in einzelnen Fällen mit denen von Auniņš identisch, oder als deren Varianten anzusehen. Deshalb wurden sie auch in die von uns veröffentlichten Texte des Auniṇš eingearbeitet, wobei sie mit Vt bezeichnet wurden. Diejenigen aber, die den Charakter selbständiger Texte haben, sind in unserem Verzeichnis mit den Nummern 51.-57. bezeichnet. Die Tatsache, daß wir einen Teil dieser Texte denen von Auniṇš als Varianten anschließen konnten, andere sogar völlig identisch mit jenen sind, könnte zur Annahme verleiten, daß Ūsinš auch

1 Auniņšs, 1905, 3, hat angemerkt: „Ferner kommt in Nr. 4 meiner Sammlung noch die Form 'Uhsenits' vor, der liebe 'Uhsin'."،

2 Auniņš 1881, 22.

3 Cf. Volteris 1890,7 ss. 
außerhalb Cesvaine bekannt sei. Da ist aber große Vorsicht geboten. Die Texte, die nicht als Varianten anzusehen sind, und nicht identisch mit den Texten von Auniņš sind, weisen Züge auf, die den Gedanken nahelegen, es seien spezielle und individuelle Dichtungen, die unter dem Einfluß der von Auniņš veröffentlichten verfaßt wurden. (Siehe Verzeichnis $\mathrm{Nr} 53,55$ u. a.).

Obwohl Volteris seine Texte nur einige Jahre nach der Veröffentlichung der Schrift von Auniņš, nämlich zwischen 1882 und 1884 gesammelt hat ${ }^{1}$, ist nicht daran zu zweifeln, daß sie unter dem Einfluß von Auninsš entstanden sind ${ }^{2}$. Ihr Inhalt bietet nichts neues.

$\mathrm{Zu}$ der in den Texten anzutreffenden Mundartform Jeusens ist anzumerken, daß sie der Sprechweise der östlichen lettischen Mundarten entspricht, wo langem - $\vec{u}$ - -ou- oder -eu- entspricht; die Deminutivendung lautet in diesen Mundarten -enš- satt -iņš- weiter westlich; $-j$ - tritt wie in den slavischen Sprachen, und hier unter deren Einfluß, vor anlautendes -e-.

2.4.1.2.2. Wie schon erwähnt, hat Barons bei der Veröffentlichung seiner Sammlung auf die Aufnahme der Texte von Auniņš verzichtet, weil er sie angesichts der scharfen Polemik für Fälschungen hielt ${ }^{4}$ Barons aber mußte feststellen, daß Lieder mit dem Namen Ūsinšs auch von anderen eingesandt wurden. Das brachte ihn in Schwierigkeiten, über deren Überwindung keine direkten Angaben vorliegen. Wieviele derartige Texte ihm eingesandt worden sind und wie groß der Anteil derer war, die er dennoch anerkannte, ist jetzt nicht mehr festzustellen. Ungeachtet dieser Schwierigkeiten sind einige Texte in seiner Sammlung doch vorhanden. Sie sind in unserem Verzeichnis mit den Nummern 58.-69. und 77.-78. bezeichnet. Einige davon, völlig identische und solche mit unbedeutenden sprachlichen $\mathrm{Ab}$ weichungen wurden den hier veröffentlichten Texten von Auniṇš angegliedert und dabei mit den entsprechenden Nummern der LD gekennzeichnet. Die inhaltliche Analyse dieser Texte, wie der vorher erwähnten werden wir später vornehmen. Die Texte bei Barons sind nicht nur aus der bekannten

1 Cf. ib. IX.

2 Šmits, 1911, 19 s, hat die Entstehung dieser Texte so ausgemalt: ,Volteris wird sich in jedem Falle an die örtlichen lettischen Priester, Lehrer und Kaufleute mit der Bitte um Nachrichten über Uিsiņ̌ gewandt haben. Diese haben im Vertrauen auf die Schrift von Auniņs und die Erklärungen von Volteris an der Echtheit der Lieder durchaus nicht gezweifelt und sich bemüht, in ihrem Raum auch solche zu erlauschen. Wenn man bestimmte Lieder energisch sucht, kann man die Sprecher leicht verwirren, besonders wenn man Getränke zu Hilfe nimmt." Es steht außer Zweifel, daß das unbegründete Vorwürfe von Śmits gegen Volteris sind, die bloß aufzeigen, wie hitzig die Diskussion geworden war.

${ }^{3}$ Cf. Endzelins 1908, 135, auch 1951, 314, § $152 \mathrm{~b}$ und die Karte bei Rūķ̣e-Draviṇa, Velta, 1959.

4 Šmits sah natürlich irrtümlich diese Handlungsweise von Barons als besonders verdienstlich an (ef. Šmits 1911, $21 \mathrm{~s}$ ). 
Gemeinde Cesvaine und dem Gebiet um Krustpils (Volteris) eingesandt, sondern auch aus anderen Gegenden Lettlands. In Anbetracht dessen, daß der Band mit den mythologischen Dainas, zu denen auch diese von ihm gebrachten Ūsiņ̌̌-Lieder gehörten, so lange nach der scharfen Polemik, nämlich 1915 herauskam, ist die Möglichkeit nicht von der Hand zu weisen, daß die Einsendung aus anderen Gegenden und der Abdruck in den LD wenigstens zum Teil auf die gesteigerte Aufmerksamkeit zurückzuführen ist.

Gleichzeitig mit dem Erscheinen zahlreicherer Texte tauchen auch neue Namensformen für Ūsiņš auf. Wenn auch in der Mehrzahl der Texte von Úsinšs die Rede ist, findet sich auch die schon bei Auniņš angemerkte Form $\bar{U}$ señ̄tis (46a) und die bei Volteris vermerkte Jeuseňš (65). Ganz neu erscheinen $\bar{U}$ sìtis (46b), $\bar{U}$ sainitis (46c), $\bar{U}$ sinitis (46d,62) und $\bar{U}$ sens (67). Von allen diesen Formen ist zu sagen, daß sie wie die Form $\bar{U}$ senitis Ablei-

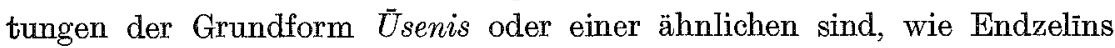
das erkannt hat. Wir finden diese im 67. Text auch wirklich, wenn zwar ohne das $-i$ - in der Endung. Diese unterschiedlichen Formen scheinen um des poetischen Ausdrucks willen, oder aus rhythmischen Gründen entstanden zu sein.

2.4.1.2.3. In der zeitlichen Reihenfolge sind nun auch die von Brastiṇš veröffentlichten Lieder zu nennen. Er faßt die Lieder thematisch zusammen und verwendet dabei in der Hauptsache die schon in den LD abgedruckten Texte. Einige Texte hat er aber auch im Folklorearchiv gefunden, wo die von Barons nicht aufgenommenen Texte (B) und später eingesandte (F) aufbewahrt werden. Von diesen Texten haben wir 7 ausgewertet, wobei 5 als V. anderen Texten zugeordnet, die übrigen unter den Nummern 70.-71. aufgeführt werden. Es ist zu vermerken, daß die Texte von Brastiņš nicht völlig sicher sind, weil er einerseits die Texte normalisiert hat, andererseits in der Mundart aufgeschriebene Texte in der Schriftsprache angepaßter Form abdruckt. In einzelnen Fällen hat er sogar deren wesentlichen Inhalt verändert $(30053,3 ; 30059,2 ; 30062$ u. a.). Was die in den von uns verwerteten Texten anzutreffenden Namensformen betrifft, so tritt neben der gewöhnlichen Form $\bar{U}$ sin̨š nur einmal im 71. Text die unbekannte Form $\bar{U} \breve{s} a s$, Nom. $\bar{U} s ̌ a$ auf. Der Sinn dieses Wortes ist im Lettischen nicht bekannt, aus den Formen des Nom. und des Gen. läßt sich auch das Genus nicht feststellen. Der Inhalt des Textes ist dazu noch rästelhaft. Es ist darin von den Töchtern des oder der Ūša die Rede. Auch diese Vorstellung ist in der lettischen Religion unbekannt. Man könnte an die Sonnentöchter denken, die aber doch zu einem anderen Komplex von Vorstellungen gehören ${ }^{1}$. Über Uša selbst sagt der Text, daß er (oder sie) spinnt und zwirnt. Diese Vorstellungen finden keinerlei Parallelen zu den übrigen Texten der

1 Näheres darüber bei Biezais 1972, 485 ss; Schröder 1, 15 ss. 
Ūsiņš-Lieder. Er steht auch in der ganzen Gruppe allein. Brastinš̆ gibt an, er habe ihn im Folklorearchiv (F 530, 2071) gefunden, woran nicht zu zweifeln ist. Dort aber lief auch sehr spätes und dabei sehr unzuverlässiges Material zusammen ${ }^{1}$. Schon vor Jahrzehnten hatte Auniņš seine Ansicht ausgesprochen, nach der der lettische Ūsiñ mit dem altindischen ușas ${ }^{2}$ in Verbindung zu setzen wäre, was die Aufnahme dieses Wortes in diesen Text hätte veranlassen können ${ }^{3}$. Diesem Text ist jedenfalls der genannten Umstände wegen keinerlei Bedeutung bei der Lösung der Frage nach Usiñŭ beizumessen.

2.4.1.2.4. Šmits, der die Ūsiñš-Lieder konsequent abgelehnt hatte und sie als späte Bildungen betrachtete, unternahm 1936 eine Fortführung der LD, wobei er auch die Textnummerierung Barons' fortsetzte. In dieser Ausgabe finden sich 6 Texte mit dem Namen Ứsinšs, von denen 3 als Varianten früher veröffentlichten Texten angefügt, die 3 anderen ihres Inhalts wegen unter den Nr. 72.-74. in unser Verzeichnis aufgenommen wurden.

Neben dem gewöhnlichen Namen tritt in diesen Texten einmal die auch schon früher (46b) vorhandene Form $\bar{U} s \bar{t} t i s$ (17 a) auf. In zwei Texten (72, 73) erscheint erstmalig $\bar{U}$ zainūtis. Diese Deminutivform ist von der Grundform $\bar{U}$ zainis abgeleitet. Das ist ein Nomen mit adjektivischer Bedeutung vom Substantiv üzas 'Hosen' abgeleitet, also der 'Behoste', ein Wesen mit Hosen, von denen es seinen Namen bekommen hat. Das erscheint auch im Text, wo in der 4. Zeile als erklärende Apposition hinter Ūaainzitis das Nomen biksainūtis der 'Behoste' auch steht. Diese beiden Texte sind die einzigen, wo in der Folklore der Name dieses Wesens von Hosen abgeleitet wird. Aber schon Stender bringt 1789 eine solche Erklärung des Namens. In einem Text finden sich auch die Mundartform Jiusēts, über die dasselbe zu sagen ist, wie über die Form Jeusen, s̆ $^{4}$.

2.4.1.2.5. Erst 1955 wurde eine Auswahl von Dainas veröffentlicht, in der eine Anzahl Ūsiņš-Lieder enthalten sind, die zum größten Teil aus früher veröffentlichten Sammlungen übernommen sind, oder es sind Varianten mit geringen sprachlichen Veränderungen schon früher bekannter Texte ${ }^{5}$. Aus dieser Sammlung haben wir 3 Texte übernommen, haben einen als Variante dem Text $9 b$ beigefügt und die zwei anderen $(75,76)$ als aus dem Material des Folklorearchives entnommene, in das Verzeichnis überübernommen. In ihnen tritt nur der gewöhnliche Name Ưsinș̌̀ auf.

1 Cf. Biezais 1961a, Anm. 39.

2 Auniņš 1881, 39.

3 Dieser Text wird auch dadurch entwertet, daß Brastinš selbst der ideologische und administrative Führer bei der Frneuerung der altlettischen Religion war, und es ist daher nicht ausgeschlossen, daß dieser Einzeltext aus jenen Kreisen kam.

1 Cf. oben S. 22 (über Jiusēts).

5 Cf. $L T d z 1,224 \mathrm{ss.}$ 
Zum Abschluß dieser Übersicht über die zugänglichen Dainas-Texte mit Aussagen über Usiņš sind folgende Erkenntnisse festzuhalten ${ }^{1}$. Erstens ist die älteste und üblichste Namensform in den Dainas $\bar{U}$ siņš sowie von dieser abgeleitete Deminutivformen und entsprechende Mundartformen. Vereinzelt treten daneben Deminutivformen von $\vec{U}_{\text {senis }}$ auf. Zweitens tritt erst in in der Mitte der dreißiger Jahre veröffentlichten Texten einigemal die Form $\bar{U}$ zainīts als direkte Ableitung von $\bar{u} z a s$ auf. Das erlaubt die Vermutung, daß diese Form in die Dainas bzw. in die Folklore erst später eingedrungen ist. Drittens zeigt diese kritische Übersicht, daß das von Auniņš veröffentlichte Material das ursprüngliche ist, das durch spätere Texte nur geringfügig ergänzt wird.

2.4.2. Das Material der Dainas wird in beachtlichem Ausmaß durch epische Folklore ergänzt. So hat schon Lerchis (1859-1903) ${ }^{2}$, als er seine Sammlung der Märchen und Sagen herausgab, in deren letztem Band 19 Texte unterschiedlichen Charakters aufgenommen, in denen Üsinšs erwähnt wird ${ }^{3}$. Dort sind auch Varianten dieser Texte abgedruckt, in denen zwar Üsinšs nicht genannt wird, die aber im Inhalt ähnlich sind und deshalb Bedeutung für das Verständnis des Üsiņš haben. Von diesen Texten hat Smits 7 mit dem Namen Usiņš und außerdem 12 Varianten abgedruckt4. Das einschlägige epische Material erwähnen wir weiter unten im Zusammenhang mit der Inhaltsanalyse.

Über die epischen Texte ist zu sagen, daß sie die Aussagen der DainasTexte bestätigen, sie aber auch ergänzen und präzisieren, wie wir das nachher bei der Erörterung des Inhalts sehen werden. In den Texten ist durchweg die Bezeichnung $\bar{U}$ siňs angewandt. Es scheint, als wäre das nicht in allen Fällen schon in der Erstaufzeichnung so gewesen. Brīvzemnieks benutzt in seinen Folkloreaufzeichnungen $\bar{U} z i n s^{5}$, was annehmen läßt, daß in seinen Texten diese Form gestanden hat, die dann bei der späteren Redigierung durch die bekanntere ersetzt wurde. Die Texte sind alle zwischen 1879, als

${ }_{1}$ Außer den hier aufgeführten Ausgaben von Dainas-Texten ist noch die sehr bedeutsame Ausgabe LTD zu nennen. Freilich sind die darin enthaltenen Texte in der Hauptsache aus LD übernommen, und die wenigen, die aus dem Folklorearchiv stammen, sind auch in den hier behandelten Ausgaben veröffentlicht. Einige Ūsinšs-Lieder hat auch Brastiņš, 1956, 73 ss, veröffentlicht, freilich ohne Finweise auf die Quellen. Weiß man, daß Brastiņ.š ein Anhänger der Erneuerung der altlettischen Religion ist, und daß er wiederholt Dainas in verschiedenem Zusammenhang unkritisch und fehlerhaft ausgewertet hat, sind dieser hier bei Seite zu lassen.

2 Über Lerchis als Sammler und Herausgeber von Folklore genauer: Zeiferts 1957 1, 139, 146 ss; Biezais 19626 ss; Bērziñš 1928.

${ }^{3}$ Cf. Pasakas 1893 \& 7,1, 310 ss, 352 s, 364 ss.

4 Cf. Pasakas 1962 s 13, 319 ss. Er hat auch eine neue Variante (11.) aufgenommen, in der aber Uিsiñ nicht genannt ist.

5 Cf. Šmits 1911, 19. 
Brīvzemnieks von Balodis die ersten Texte erhielt, und 1903, als die Texte aus der Sammlung von Lerchis gedruckt wurden, zu datieren. Man kann aber annehmen, daß auch die ältesten Texte nicht vor den von Auninšs veröffentlichten Liedern entstanden sind ${ }^{1}$. Es ist bezeichnend, daß von 1903 , als Lerchis seine Sammlung der Texte publizierte, und 1935, als Šmits seiner Ausgabe Band 13 veröffentlichte, in den er alle von Lerchis publizierten Texte übernahm, kein einziger derartiger Text hinzugekommen ist. Dafür kann es verschiedene Erklärungen geben. Es könnte sich die scharfe Polemik, die um die von Auniņš publizierten Ūsinšs-Lieder entbrannte, ausgewirkt haben, oder auch das allgemeine Versiegen der epischen Volkstraditionen.

2.4.3. Auch in anderen Volksüberlieferungsformen sind mehrere religiöse Vorstellungen vermerkt, die direkt mit Ūsiņš verknüpft sind. Brīvzemnieks hat, als er 1881 sein Material veröffentlichte, zwei Zauberformeln vermerkt, in denen Ūsiņš direkt genannt wird:

'O du starker Pferde-Úzin', stärke und beschütze meine Pferdlein! O du liebe Kühe-Màriṇa schütze und schirme meine lieben Kühe! O du reiche SchafeAñite, segne meine Schäflein! O du hurtige Ziegen-Bàrbele, erhalte meine lieben Ziegen! O du eifriger Schweine-Tenisit', mehre meine Schweinchen! O ihr lieben Schützer und Schirmer alle, schützet und schirmet mein liebes Vieh während der langen dunklen Nä.chte, sowohl im Winter als im Sommer, sowohl am Tage als in der Nacht!

In der Georgi- oder Ūziṇ[ร̌s]-Nacht tragen die Zauberer in den Pferdestall eines anderen ein Hühnerei, das mit buntem wollenen Garn umbunden ist, damit die Pferde Schaden nehmen möchten. Nachdem sie das Ei niedergelegt haben, sprechen sie: O du reicher Úzins! Dunkle Nacht, grünes Gras, ich ließ das Rößlein hinaus ins Freie. Ich ritt herbei auf einem weißen Pferde mit rotem Zaum. Mag es dir so gehen, mag es dir anders gehen. Du sollst nichts erlangen: dreimal neun magst du in den Stall hineintreiben, ein einziges wieder herauslassen! Reite den Schimmel, fahre mit dem Grauen, - man soll sie krepiert finden ${ }^{2}$.

Brīvzemnieks schreibt den Namen mit stimmhaftem -z- Ūzin̄šs. Der Inhalt der Texte erbringt keine neuen Vorstellungen über Ūsiņ̌. Die Datierungsfrage ist komplizierter. Die Sammlung von Brīvzemnieks ist 1881 herausgekommen, also im selben Jahr wie die Liedertexte von Auniņš. Deshalb ist es am Platze zu fragen, ob die von Brivzzemnieks gebrachten Texte etwa unter dem Einfluß von Auniņš entstanden sind. Nach dem Er-

1 Das anzunehmen legt auch der Umstand nahe, daß in der sorgfältigen Bibliographie von Vilma Greble, 1971, keine Angabe darüber ist.

2 Brīvzemnieks, 1881, $190 \mathrm{~s}$, mit einer russischen Übersetzung. Abgedruckt bei Auniņš, 1881, 35, mit deutscher Übersetzung. Unsere Übersetzung ist von Aunin̨š übernommen.

3 Das haben schon Aunin̄̌, 1881, 36, und Šmits, 1911, 19, angemerkt. 
scheinungsjahr der Arbeiten wäre die Frage negativ zu beantworten. Smits aber im Eifer seiner Polemik ist überzeugt, daß diese Texte unter dem Einfluß der von Auniņš publizierten Lieder entstanden sind ${ }^{1}$. An den Einwänden von Smits aber sind Zweifel erlaubt, denn er nennt keinerlei Begründungen für dieselben. Der Hinweis darauf, daß die Texte in der Sammlung von Brīvzemnieks aus anonymer Quelle stammten, ist ohne Bedeutung, da das im 19. Jh. veröffentlichte Folklorematerial weithin überhaupt anonym ist.

Zu der gleichen Gruppe religiöser Vorstellungen gehören auch Aussagen, die Straubergs vermerkt hat.

Beim Hinaustreiben der Pferde zur nächtlichen Hütung erfolgten ähnliche Maßnahmen. Dort, wo man bei der nächtlichen Hütung Eier gekocht und dem Ūzinš zum Opfer gebracht hat, hat man auch sie bei der Wahrsagung benutzt; sie hätten erkennen lassen, ob es den Pferden gut gehen würde. Auch dort hätte bloß der Älteste Üziṇš zu Ehhren mit dem Essen beginnen dürfen. Wenn man zur nächtlichen Hütung ritt, mußte man für jedes Pferd 5 Eier mitnehmen; vier durfte man essen, das fünfte aber war unter die Pferde zu werfen, und die Pferde darüber hinzutreiben; das Pferd, welches das Ei zertrat, das verendete in dem Jahr. In der Gemeinde Belava hatte ein Zauberer gewohnt. Jedes Frühjahr sei man zu ihm das erste Mal zur nächtlichen Hütung geritten. Man habe Eier mitgenommen, dieselben gekocht und gegessen. Dort haben sie auch Eier gekocht und sie unter die Pferde geworfen; dann haben sie die Pferde gehetzt und welches Pferd ein Ei zertreten hat, daß mußte in dem Jahr verenden ${ }^{2}$.

Aus den in diesen Texten gemachten Hinweisen ist zu sehen, daß die in ein paar Fällen vermerkte Tradition von der gleichen Person und vom gleichen Ort stammt. Es scheint, daß die Schreibweise Ūziņš von Straubergs stammt und nicht im Originaltext steht ${ }^{3}$. Inhaltlich bietet diese seine Nacherzählung der Überlieferung nichts Neues. Straubergs hat offenbar auch nicht beabsichtigt, Nachrichten über Usinšs zu bringen. Er spricht von Ūsinšs nur indirekt, denn seine Absicht war, eine Überlieferung, die von der Nutzung von Eiern zur Wahrsagung handelt ${ }^{4}$, zu charakterisieren.

Hier sind noch einige Äußerungen, die Smits in seiner Sammlung unter der Kennzeichnung , Usiņš-Tage " abdruckt:

Am Burtnieki-See nennen die alten Mütter Uzzinš oft. Wenn sich ein Unwetter erhebt, rufen sie den Kindern zu: ,Kinder flieht. Uza kommt!“ T 31411

1 Cf. Smits 1911, 19.

2. Straubergs 1939, 131. Er hat in seiner Arbeit auf derartige Texte verwiesen, die sich im Folklorearchiv befinden, statt sie aber unverändert abzudrucken, erzählt er bloß ihren Inhalt wieder. Deshalb haben seine Hinweise nur sekundüre Bedeutung.

3 Da die Tradition in Belava aufgezeichnet wurde, ist zu erwarten, daß das in der Mundart erfolgte und hätte sie die bekannte Form Jeuseņs enthalten müssen.

4 Über die Benutzung der Eier zum Wahrsagen vgl. auch Haberland 75. 
Ūsiņš ist in der Mitte von Latgale unbekannt, wahrscheinlich nur an den Grenzen mit Vidzeme. T 31412

Der Hahn muß unter der Krippe geschlachtet werden, denn dann gibt man das Blut Üsiṇš ab, damit er die Haustiere segne. T 31414

Der erste Text ist in Burtnieki niedergeschrieben, der zweite an unbekanntem Ort in Latgale, der dritte in der Gemeinde Lubāna ${ }^{1}$. Smits gab seine Zusammenstellung, bei der er sich hauptsächlich auf das Material des Folklore-Archivs stützt, in der zweiten Hälfte der 30er Jahre heraus. Man hätte nun erwarten können, daß sich in diesem Archiv ein umfangreicheres Material angesammelt hat. Aber auch hier ist $\mathrm{zu}$ konstatieren, was wir im Zusammenhang mit dem epischen Material gesagt haben. Es ist beschränkt, ja dürftig.

Diese drei Texte erbringen nichts Neues für das Verständnis des Wesens von Ūsinšs. Der zweite ist das Ergebnis einer direkten Befragung darüber, ob Ūsiņš auch in Latgale bekannt ist. Dem Befragten konnte es schon scheinen, daß der dort nicht bekannt ist. Aus dem von Volteris gebotenen Material aber wissen wir, daß U siņš, in Latgale doch bekannt gewesen ist. Während wir in den beiden letzten Texten die gewohnte Namensform

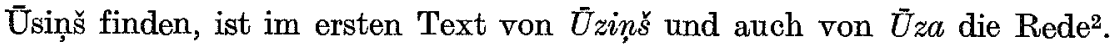

Dieser Quellengruppe ist auch ein Sprichwort zuzrechnen, daß erst 1957 abgedruckt wurde: „Er lebt wie $\bar{U} \operatorname{sins{}^{3}}$. Da nähere Angaben über Ort und Zeit der Aufzeichnung fehlen, muß man sich mit der Feststellung zufriedengeben, daß der Name $\bar{U}$ siņš auch in ein Sprichwort aufgenommen wurde. Dagegen bestehen keine Schwierigkeiten für die Feststellung der semantischen Bedeutung des Wortes, denn daneben sind mehrere ähnliche Varianten abgedruckt, in denen an der Stelle $\bar{u}$ siņš Wörter wie bajärs 'Edelmann', leimanis 'Freibauer', birgers 'Bürger' u. a. stehen. Die Synonyme zeigen auf, daß das Wort $\bar{u}$ siņš hier zur Kennzeichnung allgemeinen Wohl-

1 Smits hat dortselbst noch einen Text (T 31410) veröffentlicht, den er selbst in der Gemeinde Galgauska gehört habe und in dem gesagt ist, daß man „Ūsiņš für den Bienengott hält". Die Handlungsweise von Smits ist in diesem Falle unverständlich. Er macht Auniņš die schärfsten Vorwürfe darüber, daß der seine Quellen, nämlich die Gewährsleute, nicht nennt, Šmits aber tut das bei diesem Texte selbst nicht. Da das Material über Ūsiñ als Bienengott äußerst beschränkt ist, kann dieser Text mit seiner Unsicherheit nicht verwertet werden, was zu bedauern ist.

2 Barons hat in LD, 344, einen Text aufgenommen, der den Namen Ussinš enthält, der aber in Wahrheit ein Rätsel ist. Eine Variante dieses Rätsels hat schon Brīvzemnieks, 1881, 96, Nr. 1248-49, veröffentlicht; es enthält an Stelle von üsiňs - üpātis. Später erschienen weitere Varianten dieses Rätsels mit üstinžs und ūkstītis (cf. Mĩlklas 76, Nr. 463, a, d). Die Lösung aller dieser Rätsel ist „,das Kind“" und die darin anzutreffenden Namen sind frei verwendbare Kosenamen.

${ }^{3}$ Sakāmvāra 291 , Nr. 6435. 
habens benutzt wird. Es scheint aber, daß das eine späte Erweiterung der Bedeutung des Wortes ist.

2.5. Thre Stelle bei der Erörterung des Ūsiṇš-Problems ist auch der Toponymik zuzuerkennen. Bei seiner ersten Veröffentlichung der Ūsiṇš-Lieder 1881 sagte schon Auniṇs: ,,Zu meiner großen Ueberraschung fand ich [...] in der Nachbarschaft [von Cesvaine] [...] auch einen Uhsina kalns (UhBingBerg) einen Uhsiṇa krohgs (Uhßing-Krug) und eine Uhsinga māj (UhßingGesinde) vor [...]." "1 Dank der Veröffentlichungen der letzten Jahrzehnte ist jetzt eine größere Anzahl von Ortsnamen (ON) bekannt, in denen wir den Namen Üsiņš und mit ihm verwandte Namensformen antreffen. En. dzelīns veröffentlichte schon zwischen 1922 und 1925 zwei Bände, die sämtliche Ortsnamen Lettlands enthalten². Danach begann Plāķis 1936 die Veröffentlichung seiner ON-Sammlung, die freilich nicht beendet wurde und nur Kurzeme und Zemgale erfaßt. Durch die Herausgabe dieser zwei Sammlungen ist, soweit sie die gleichen Provinzen erfassen, die Möglichkeit gegeben, die beiden Quellen zu vergleichen und damit größere Sicherheit zu gewinnen. Beide Ortsnamensammler sind Sprachwissenschaftler und haben sich bemüht, die Aussprache der Namen zu kennzeichnen, indem sie auf die unterschiedlichen Akzente, die Vokallänge und andere Aussprachemerkmale hinweisen. Besonders Plāksis war bemüht, selbst die ON aufzuschreiben und an Ort und Stelle deren Aussprache zu erlauschen. Hier sind, soweit es mir möglich war, alle ON aus der Sammlung von Endzelins aufgezählt, und wenn ein solcher ON auch bei Plākis auftritt, ist dieser in Klammern hinzugefügt. Die Namen sind in der Reihenfolge geordnet, die sich in der Arbeit von Endzelins findet. Zuerst wird die Gemeinde genannt, in der der ON zu finden ist, danach der Ortsname selbst und eine Ziffer, die die Seite in den Arbeiten der beiden Sammler angibt.

Zum größten Teil sind es Namen von Bauernhöfen; handelt es sich im Einzelfall um andere in der Natur anzutreffende Orte, wird es besonders vermerkt.

Kalsnava - ušāni, 14; Saikava - ušāni, 27; Tlukste - ūsani, 39; Koknese - üsini, $\bar{u} z e ̨ n i, 45$; Piṇki - uš(i)nas, 54; Anna - ûsini, 67; Bilska usiňs, 68; Galgauska - ùsini, 71; Litene - ùsiñi, 79; Vainiži - uša, 111;

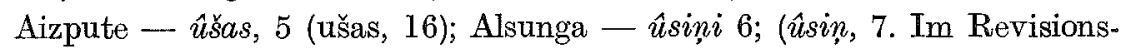
verzeichnis von 1850 ist der PN uhsing vermerkt, 11); Laža - $\hat{u}$ šas, 18 (Im Revisionsverzeichnis von 1857 ist $\mathrm{ON}$ whsche vermerkt, 46); Tāšu - Âsi,

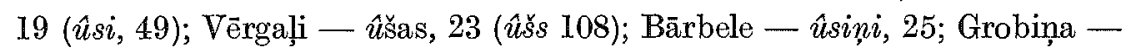

1 Auniņš 1881, 7. Cf. auch id. 1913, 22.

2 Diese Sammlung von Endzelīns wurde mit Ergänzungen 1956 neu aufgelegt, aber die Ausgabe reicht nicht bis zum Buchstaben $U$. 


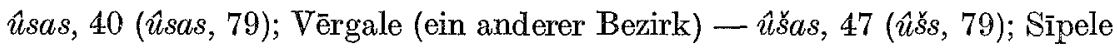

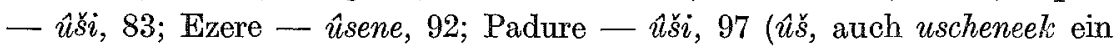
Berg und ein Tal, in jetziger Schreibweise ušenieki); Virbi - $\hat{s} s a s, 111$;

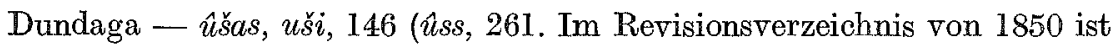
der PN usche |uhsche, in heutiger Schreibweise uše $\| \bar{u} s ̌ e)$; Edole - üsinu kalns (Berg), 148 (ûsiṇkalns, 264); Unguri - ušęni, 173; Plāķis hat weiter vermerkt Gemeinde usaik, $i$ mit dem Gut usaik,i, Ziegelei usaik,i und Schlucht usaiki 71 .

Bei der Auswertung dieser ON und Personennamen (PN) sind die Schwierigkeiten zu beachten, auf die schon die Herausgeber des Materials selbst verwiesen haben. Besonders betont das Endzelīns, der sich oft mit dürftigen und unvollständigen Angaben über die Aussprache und die Rechtschreibung der Namen abfinden mußte ${ }^{1}$. Die hier veröffentlichten Namen zeigen unmißverständlich, daß nebeneinander Ableitungen mit den Wurzeln $\bar{u} s$ und $\bar{u} z$ anzutreffen sind. Zur Wurzel $\bar{u} \breve{s}$-ist am häufigsten die maskuline Pluralendung $-i$, oder die feminine Pluralendung -as getreten. Beide ONAbleitungsweisen sind sehr verbreitet und eine gewöhnliche Erscheinung bei der Bildung lettischer Ortsnamen. Neben diesen Formen sind Ableitungen mit -iņš, sowohl in der Einzahl (üsinšs), als auch in der Mehrzahl

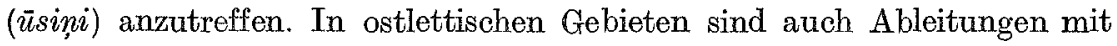
-āns in der Mehrzahlform (ušāni) zu finden. Endzelīns und Plāksis haben, soweit ihnen das möglich war, auch die Intonation vermerkt. Wie das obige Verzeichnis zeigt, stimmen ihre Beobachtungen im Ganzen überein. Wichtig ist die Frage nach der Länge des Wurzelvokals $u$. In einzelnen Fällen ist er, scheint es, kurz gewesen, in der Mehrzahl der ON vermerken die Herausgeber in der praktischen Aussprache einen langen Vokal. Daß in diesem Falle keine weitgehenden Konsequenzen zu ziehen sind, und daB man sich kaum irgendwie festlegen kann, lassen die seltenen Fälle erkennen, wo derselbe $O N$ bei jedem der beiden Autoren mit jeweils anderer Intonation und anderer Vokallänge angegeben ist, so schreibt Endzelīns in Aizpute

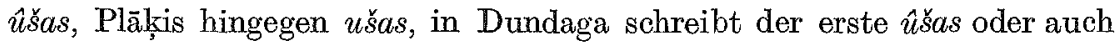

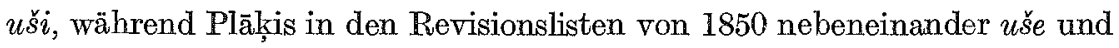
$\bar{u} s ̌ e$ findet. Die Endung $-e$ ist aus dem Einfluß der oben erörterten deutschen Schreibweise zu erklären.

Das Material zeigt auch weitere Eigentümlichkeiten der Schreibung und der Aussprache, die in unserem Zusammenhang von geringerer Bedeutung sind.

Die gegenwärtige Forschungslage gestattet nicht mehr als die Feststellung der Tatsache, daß nebeneinander die beiden Wurzeln $\bar{u} s$ - und $\bar{u} \breve{s}$-auftreten. Ebenso sind nebeneinander langes und kurzes - $u$ - als Wurzelvokal anzu1 Cf. Endzeling 1922, 3 ss. 
treffen. Dennoch ist die Tatsache besonders zu betonen, daß die Form $\bar{u}$ šas und $\bar{u} s ̌ i$ nicht weniger verbreitet ist als $\bar{u}$ siņs. Das ist vor allem deswegen erforderlich, weil es an die Schreibweise von Stribiņš 1606 Usching erinnert. Noch wichtiger für die Einsicht in die etymologischen Zusammenhänge ist die Verbreitung der in unserer Liste genannten Namen in Lettland. Diese zeigt unmißverständlich, daß die von Auniņš ausgesprochenen Gedanken, wonach in ganz Lettland ON bekannt sind, die an die von ihm beschriebene Úsiņš-Tradition gebunden sind, begründet sind. Die sind weit außerhalb von Cesvaine und dessen Umgebung verbreitet, auf welchen Raum sie Šmits zu seiner Zeit beschränken wollte. Die ON von Endzelins und Šmits reichen nur bis zum Jahre 1850 zurück. Das erklärt sich aus dem Umstand, daß die Letten PN und in großem Ausmaß die Hofesnamen erst nach der Befreiung aus der Leibeigenschaft 1817-1819 offiziell erhielten. Noch später, erst in der 2. Hälfte des 19. Jhs. konnten sie mit dem Ankauf ihrer Höfe beginnen ${ }^{1}$. Weitere Utberlegungen und Forschungen erfordert die Erscheinung des Zusammenhangs von Hofes- und Personennamen. In unserer Liste finden sich zwei derartige Fälle. Endzelīns vermerkt in der Gemeinde Alsunga den Hofesnamen ûsini, denselben Hof nennt dort auch Plāksis, er hat aber in der Revisionsliste von 1850 auch den PN uhsing (bzw. üsiņ̧̌) in der damals üblichen Schreibweise gefunden. Der zweite Fall ist aus Dundaga.

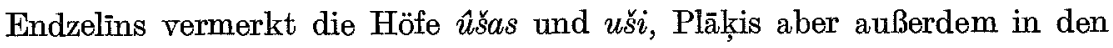
Revisionslisten von 1850 auch die PN uše und $\bar{u} s ̌ s$. Das zur Zeit verfügbare Material ermöglicht in keinem der beiden hier genannten Fälle eine Aussage darüber, ob der PN nach dem schon bestehenden Hofesnamen gegeben wurde, oder umgekehrt, ob der Hof nach dem schon vorhandenen PN benannt wurde. In beiden Fällen aber ist die Behauptung begründet, daß dieses Wort sowohl als PN, wie als ON bekannt war.

In einigen wenigen Fällen ist der Nachweis viel älterer Dokumentation möglich, die vom Auftreten des Namens Ūsiņš als ON und als PN zeugt. Die schwedische Regierung führte zur Zeit Karls XT eine Vermessung von Vidzeme durch, die die Grundlage für die Steuern an den Staat geben sollte. Aus jener Zeit sind Karten mit Verzeichnissen von ON und PN erhalten ${ }^{2}$. Bei Einsicht in dieses Material erweist sich, daß es ON und PN gibt, die schon Jahrhunderte bestanden, und die dann später in der Arbeit von Endzelins wieder erscheinen. Da die Schweden nur in Vidzeme geherrscht haben, kann hier nur von den Namen in dieser Provinz die Rede sein.

Da finden wir im Gebiet der Spilve den PN usgh Thomas in der damaligen schwedischen Schreibweise. Das bezieht sich auf 1683, als die Vermessung

1 Darüber genauer Cimermanis 14 ss; Švābe 1958, 302, auch 1928, 341 ss.

2 Darüber haben sich in ihren Arbeiten eingehender geäußert Vasar 335 sS; Dunsdorfs 1,24 ss. 
erfolgte und auf 1686, als das Verzeichnis der Bauern fertiggestellt wurde ${ }^{\mathbf{1}}$. Aus der gleichen Zeit sind auch deutsche Quellen erhalten, in denen dasselbe Wort Usche geschrieben wird ${ }^{2}$. Wir haben auch bei Endzelīns festgestellt, daß er in derselben Gemeinde Piņ̧̣i in den ersten Jahrzehnten dieses Jhs. den Hofesnamen $u s(i)$ nas nennt ${ }^{3}$. Vergleicht man die deutsche, schwedische und lettische Schreibweise, erweist sich zweifelsfrei, daß man es in allen Fällen mit demselben Wort zun tun hat. Dieser Vergleich zeigt aber, daß neben der in den älteren Quellen erhaltenen Grundform, bei Endzelīns die Verkleinerungsform erscheint, was für die weitere Erörterung unseres Problems von Bedeutung ist. Außerdem scheint es, abgesehen von der schwedischen Schreibweise, daß in der Wortwurzel ursprünglich der Zischlaut -š- vorhanden war.

Wie stark im Laufe der Zeit die ON und PN sich verändert haben, sieht man aus Endzelins' Verzeichnis. Unter den von uns genannten Wörtern seiner Sammlung findet sich aus verständlichen Gründen der Name Uিsani nicht ${ }^{4}$, weil man daran zweifeln darf, daß dieser Hofesname eine etymologische Beziehung zu Ūsiņš hat. Das jetzt veröffentlichte Höfeverzeichnis zur Karte von 1682 enthält in der Gegend von Ikšķile zwei Höfe, die schwedisch $V$ singh und deutsch $U$ sing genannt werden ${ }^{5}$. Damit ist bewiesen, daß in der 2. Hälfte des 17. Ths. auch in dieser Gegend der Hofesname $\bar{U}$ sini bekannt war, der sich jedoch später stark verändert hat.

In der Beschreibung von Madliena sind zwei verschiedene Hofesnamen genannt, die schwedisch Usken, deutsch in einem Falle Ukkan, im anderen $U$ sjan geschrieben werden ${ }^{6}$. Endzelins vermerkt dort $U t \not k e n i$ und $U z ̌ e n i^{7}$, weshalb auch kein Anlaß bestand, diese beiden von ihm genannten Namen

1 Cf. Dunsdorfs 2, 29 (Signum auf der Karte 28,7). In der Eintragung ist zu lesen, daß mehrere Bauern aus der Spilve bezüglich der Abgaben zu Hof Pinkzi gehörten. Es ist aber nicht klar gesagt, daß auch der hier genannte Thomas usgh dazugehörte. Dunsdorfs schreibt fehlerhaft $U \beta g h$ (ib. 37).

2 Die deutsche Schreibweise des Namens ist von Dunsdorfs, 2, 37, übernommen. Leider hat dieser nicht angegeben, ob er ihn von Bücher, 1923 s, oder aus dem Hakenrevisionsbuch (VA, Vol. 11) übernommen hat.

3 Cf. Endzelins 1922 \& 1, 54.

4 Cf. ib. 39.

5 Cf. Dunsdorfs 2, 99. Die deutsche Schreibweise hat er aus dem Hakenrevisionsbuch von 1687 (VA, Vol. 11) übernommen. Ich hatte keine Möglichkeit, in diese Originaldokumente Einblick zu nehmen, weil diese Archivalien in Riga der freien Forschung nicht zugänglich sind. Dunsdorfs in deutscher und schwedischer Schreibweise wiedergegebene Namen müssen mit den Originalen verglichen werden, weil seine Lesungen in mehreren Fällen fehlerhaft sind.

6 Cf. Dunsdorfs 2, 173 (Sign. 5,5 und 5,9) hat den zweiten Namen fehlerhaft Ußken geschrieben. Das Faksimile zeigt bei beiden Namen die Schreibweise Usken.

7 Cf. Endzelïns 1922 s 1, 48. 
in die oben behandelte Übersicht der $\mathrm{ON}$ aufzunehmen. Diese von der heutigen lettischen so stark abweichende deutsche und schwedische Schreibweise aus dem 17. Jh. verursacht große Schwierigkeiten, diese Namen mit dem Namen Ūsinš zu verbinden. Das ist im ersten Falle wegen der Reihe Usken, Ukkan, Utkeni nicht möglich, wogegen es im zweiten Falle doch glaubhaft erscheint. In diesem Falle muß man freilich die schwedische Schreibweise Uskan, die in beiden Fällen gleich ist, als stärker verkrüppelt als die deutsche Schreibweise Usjan ansehen. Entsprechend der Schreibweise von Endzelīns wäre es heute Uženi. Da im Lettischen allgemein ein starkes Schwanken im Gebrauch des Suffix -ēns und -āns, wie im Gebrauch von ž und š statt hat, kann man annehmen, daß dieser Hof in Madliena im 17. Jh. Ušani geheißen hat und mit Ūsiņš zu verbinden ist.

Der von Endzelīns in der Gemeinde Bilska1 vermerkte Name $\hat{u}$ siņ $̋$ entspricht geographisch dem Namen, der in der Karte des Gebietes von Rauna aus dem Jahre 1681 schwedisch $V$ singh und deutsch $U$ hsing geschrieben wird $^{2}$. In diesem Falle ist die Identifizierung ohne Schwierigkeit. Ungeachtet der unterschiedlichen Schreibweise ist das Grundwort Ūsinšš

Das Deskriptionsbuch von Koknese weist in schwedischer Schreibweise Vsingh und in deutscher Ussing auf4, was mit dem uns bekannten, von Endzelīns aufgezeichneten $\bar{u} s i n i$ übereinstimmt und hier keinerlei Erläuterung bedarf.

Trhalten ist auch die Karte von Cesvaine, das dazugehörige Deskriptionsbuch aber fehlt. Dennoch ist eine deutsche Schreibweise des Namens Uhsing erhalten ${ }^{5}$. Dieser Hof hätte sich in der Gemeinde Kārzdaba befunden. Hier muß man zu Auniņš zurückkehren, der in seiner ersten, 1881 veröffentlichten Arbeit gerade auf diesen Hof mit dem Namen Ūsiṇš als Beweis dafür verwiesen hat, daß die Tradition alt se $^{6}{ }^{6}$, nämlich zum mindesten bis zu den 8oer Jahren des 17. Jhs, reicht.

Mehrfach treffen wir diesen Namen auf der Karte von Bērzaune. So findet sich in der Gemeinde Kalcenava die schwedische Schreibweise Usian und die deutsche Uschen, was dann bei Endzelins als ušāni erscheint? Tm

1 Cf. ib. 68.

2 Cf. Dunsdorfs 2, 222 (Sign. 31,33). Die deutsche Schreibweise stammt aus dem Hakenrevisionsbuch von 1688 (VA, Vol. 14).

3 Cf. oben S. 64.

4 Cf. Dunsdorfs 2, 245. Deutsche Schreibweise aus dem Hakenrevisionsbuch von 1688 (VA, Vol. 12). Aus der gleichen Quelle vermerkt er den zweiten Hofesnamen Ussing. Cf. Endzelīns $1922 \mathrm{~s}, 1,45$.

5 Cf. ib. 296. Das deutsche Wort von RA, Uthräknings Book, Nr. 901 g.

(Cf. oben S. 46.

7 Dunsdorfs 2, 311 (Sign. 43,94). Deutsche Schreibweise aus Hakenrevisionsbuch (VA, Vol. 14 und RA, Vol. 6). Cf. Endzelins 1922 s 1, 14. 
Gebiet des Gutes Kūja findet sich in der Gemeinde Lazdona die schwedische

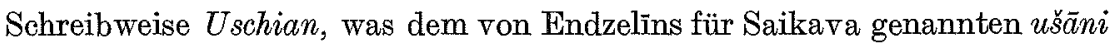
entspricht1. Wenn der für Kalcenava in schwedischer Schreibweise Usian genannte Hof bei Endzelīns dem $u s ̌ a ̄ n i ~ e n t s p r i c h t, ~ b e s t e h t ~ k e i n ~ A n l a ß$, daran zu zweifeln, daß auch der schwedisch geschriebene Name Usian in Bërzaune $^{2}$ ušāni entspricht. In der Zusammenfassung ist zu sagen, daß dieses Material aus dem 17. Jh. unmißverständlich bestätigt, daß der Name Usinšs, wenn auch unterschiedlich geschrieben in allen lettischen Gegenden von Vidzeme bekannt und verbreitet war, während er offenbar in den livischen Gebieten fehlt.

Diese Toponymik bestätigt, daß neben Ableitungen von $\bar{u} s-$ auch ON und PN vorkommen, die von der Wurzel $u_{s} s$ - abgeleitet sind.

2.6. Bei der Behandlung der PN, in denen das Wort Ūsinš oder von derselben Wurzel abgeleitete ähnliche Wörter vorkommen, finden wir die allerinteressanteste Nachricht bei Blese. Er hat in seiner Monographie auch einige genannt, an denen wir nicht vorbeigehen können ${ }^{3}$. Ihm war das ,grobinsch Kirchen Buch von Ano 1584-1614" zugänglich, in dem auf S. 25 im Jahre 1609 ein Name vermerkt ist, der lettisch sein kann: [...] Vsings [... $]^{4}$. Diese von Blese erwähnte Eintragung ist in zweierlei Hinsicht von großer Bedeutung. Wir haben oben festgestellt, daß sowohl Endzelīns, wie Plākis für

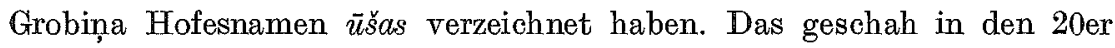
Jahren dieses Jhs. Nun lesen wir, daß in derselben Gemeinde Grobina eine Person lebte mit dem Familiennamen Vsings, was in heutiger Schreibweise unmißverständlich Ūsiņš heißt. Da nähere Angaben fehlen, können wir nicht behaupten, daß der von Endzelīns und Plākisis genannte Hofesname direkt mit diesem PN zu verknüpfen ist. Die Tatsache aber bleibt bestehen, daß beide Namen aus derselben Gemeinde stammen, und deshalb ist wohl anzunehmen, daß es so ist.

Weiter ist es von besonders großer Bedeutung, daß diese Eintragung von 1609 in Grobina erfolgte, also in einem ganz anderen Gebiet, als dem, in dem Auniņš seine Lieder aufgeschrieben hat. Es bestätigt sich damit ein weiteres Mal, daß das Wort keine Bildung späterer Zeit ist, sondern daß es als PN schon mehrere Jhe. im Gebrauch war. Zeitlich paßt es zu den bei der Missionsreise des Stribiņš entdeckten Gottesnamen.

1 Cf. ib. (das Signum fehlt auf der Karte). Cf. Endzelīns 1922 s 1, 27.

2 Cf. ib. 307 (Sign. 1,8). Eine deutsche Schreibweise des Namens fehlt, und bei Endzelins ist es überhaupt nicht verzeichnet.

3 In seiner Arbeit sind auch alle die Namen aufgeführt, die schon Plāķis in seiner Arbeit aufgezeigt hat.

4 Blese 25. Leider hat er nicht angegeben, wo diese Handschrift aufbewahrt wird. Aus einer Anmerkung ist freilich zu entnehmen, daß es sich in Riga befunden hat. 
Blese nennt in seinen PN-Listen noch einige weitere Namen, die von derselben Wurzel abgeleitet sind. Aus den Listen der Rigaschen Landvogtei hat er Andres Usz, übernommen, der dort 1607 eingetragen wurde'. In den Revisionslisten von Smiltene ist 1601 der Familienname Usin ${ }^{2}$ vertreten. In diesem Falle ist die Sicherheit vollkommen, weil uns drei von einander unabhängige Quellen verfügbar sind. Da ist erstens der von Endzelins in der Gemeinde Bilska, die tatsächlich zum Gebiet von Smiltene und Rauna gehört, erwähnte Name $\hat{u} \operatorname{sins.~Die~zweite~Quelle~ist~die~Anmerkung~in~der~}$ Karte von Rauna aus 1681, wo in schwedischer Schreibung Vsingh, in deutscher $U$ hsing steht. Die dritte Quelle ist der eben genannte Name $U s \sin$ aus dem Gebiet von Smiltene. Die Identität ist sicher und die Kontinuität seit 1601 erhalten. Dieser im Jahre 1601 feststellbare Name Ussin (Ūsiņš) gerade im Raum von Smiltene gewinnt dadurch besondere Bedeutung, daß Smits 1911, also so sehr viel später schreibt: ,Aus dem Raum von Smiltene und Rauna ist mir nur bekannt, daß dort früher ein alter Mann mit dem Familiennamen Ūsiņš gewohnt hat, den die Leute aber nur Üzịnu (Acc.) Nom. Ūziņš genannt haben. "3 Damit hat sich der Name Ũsiňš seit dem ersten uns bekannten Datum, 1601, bis in die Zeit hinein erhalten, in der Smits ihn zu Anfang dieses Jhs. gehört hat. Die Bemerkung am Ende des Zitats ist bedeutungslos. Wenn dieser Mensch tatsächlich zu Beginn des 20. Jhs. Uziņš genannt worden sein sollte, dann ist das eine späte Abwandlung, denn die Eintragung von 1601 enthält Ussin mit -ss-, was mit Sicherheit anzeigt, daß die ursprüngliche Aussprache die mit dem stimmlosen $s$ war. Fs kann aber auch sein, daß Smits selbst er nicht gehört hat, denn er formuliert, es sei ihm bekannt, daß man den Namen mit $z$ gesprochen habe. Auf jeden Fall hilft die Eintragung vom Namen Ūiňš zur Festigung der Anschauung, daß die ursprüngliche Aussprache ein s hatte. Ähnliche Familiennamen sind in noch älteren Schriften zu finden. So hat 1582/83 in Roja ein ,Paul $U \beta e^{6}$ und in Neveja bei Dundaga ein ,Jacob $U \beta e^{، "}$ gewohnt $t^{4}$. Auch diese Familiennamen veranlassen zwei Anmerkungen. Erstlich schließt die Schreibweise mit $s z$ die Möglichkeit aus, ein stimmhaftes $z$ zu sprechen. Die Bezeichnung des Lautes durch $s z$ erlaubt nur die Aussprache $s$ oder $\breve{s}$, wie schon oben gesagt 5 . Die andere hier erforderliche An-

1 Bücher 1, 327. Hier muß man auch die Bemerkung Bulmerincqs beachten: ,Weiches s wird hier und wieder durch $\mathrm{z}$, hartes $\mathrm{s}$ durch sz wiedergegeben, z. B. zat neben sat, alze neben alse, Vrobozen neben Vrobosen; Vosz, isz, huszsluter" (ib. 5). Auch Bulmerineq 282, und Blese 269.

2 Šväbe 1921, 10, auch Blese 269.

3 S. Smits 1911, 24; cf. auch Auniṇš 1913, 19.

4 Bielenstein 1892, 260; auch Arbūzovs 221, 225; Blese 337.

5 Cf. oben. S. 69. Gegen Šmits muß weiter angeführt werden, daß S̆vābe, 1927, [16], gerade aus dem Gebiet Smiltene, Waldleute Gemeinde (Meža laužu pagasts) im Jahre 
merkung bezieht sich auf den Ort, wo diese Namen erscheinen, nämlich Roja und Dundaga. Bei der Besprechung der ON hatten wir gesehen, daß gerade im Raum Dundaga Endzelīns und Pläksis die Hofesnamen von $\hat{u} \hat{s} a s, u s ̌ i, ~ \hat{u s s ~ g e f u n d e n ~ h a t t e n ~ u n d ~ P l a ̄ k ̧ ̧ i s ~ d a z u ~ i m ~ R e v i s i o n s v e r z e i c h n i s ~ v o n ~}$ 1850 die PN uše/ūše. Jetzt können wir konstatieren, daß bei Ersetzung der deutschen Endung -e durch die richtige männliche Endung dieser Name $\bar{u} s ̌ s$ oder auch $\bar{u} s ̌ a$ geheißen hat. Diese Einsicht führt uns in noch fernere Vergangenheit zurück. Das bestätigt, daß ein solches Wort schon 1582-83 in Lettland weit außerhalb des oft genannten Cesvaine bekannt war.

Aus den polnischen Revisionsakten von 1599 hat Blese noch einige Namen übernommen, die hier diskutiert werden müssen, nämlich aus dem Raum Koknese Jakób Uzen und Jeźy Uzen'. Da in diesem Wort ein stimmhaftes $z$ enthalten ist, wäre zuerst anzunehmen, daß der Name von dem bekannten Wort $\bar{u} z a s$ 'Hosen' abgeleitet ist. Dennoch ist das nicht so, denn auch in diesem Falle haben wir bei Endzelīns für Koknese zwei Hofesnamen vermerkt gefunden - üsini und ūzen. Der Schreibweise der PN entspricht vollkommen der zweite Hofesname üzęni. Der andere Hofesname üsini läßt erkennen, daß die Erklärung des Namens $\bar{u} z e ̨ n i$ nicht bei dem ähnlich klingenden $\bar{u} z a s$ zu suchen ist. Die polnischen Beamten, die diese Dokumente geschrieben haben, ließen sich bei der Schreibweise lettischer Wörter naturgemäß von ihrem phonetischen System, oder besser von ihrem Gefühl leiten, genau so, wie das vorher und nachher die Deutschen getan hatten. So konnten beide genannten PN Uzen entstehen.

Auch in diesem Falle herrscht Sicherheit, denn wir verfügen über drei von einander unabhängige Quellen. Die erste ist die eben erwähnte polnische Revisionsakte von 1599 mit der Eintragung Uzen, dann das schwedische Deskriptionsbuch für Koknese von 1680 mit der schwedischen Eintragung $V$ singh und der deutschen Ussing und schließlich die Quelle des Endzelīns von 1922 mit $\vec{U}$ sini bzw. Usęni. Diese über die Jhe. bewahrte Kontinuität zeigt, daß alledem der richtige lettische Name $\bar{U}$ sings zugrundeliegt, sei das Wort in polnischer, schwedischer und deutscher Schreibweise auch noch so sehr verdorben. Diese Einsicht hat prinzipielle Bedeutung, denn es wirft ein Licht auf die Fälle, wo uns das Wort üsiņš mit stimmhaftem z entgegentritt. Hier kann man sich nochmals dem Smiltener Bauern mit dem ursprünglichen Namen $U \sin$ (Ūsiņš) and dem später von Šmits behaupteten Üziṇš erinnern.

Aus derselben Quelle erwähnt Blese noch, daß im Raum Koknese ein

1630 ein Bērtulis $\widetilde{U} \sin , s$ (leider nicht in der Schreibweise der Originalhandschrift)

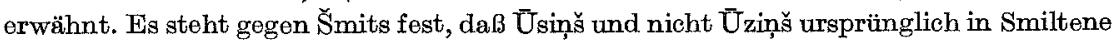
vorkommt.

${ }^{1}$ Polska 80 s; auch Blese 337. 
„Marko Usianianis “ gewohnt hat, was er als üsin̨ęns liest1. Für diese seine Lesart gibt er keine Erklärung. Es scheint, daß das nur frei geraten war, weil es schwer zu glauben ist, daß die echt lettische Endung -is grundlos durch eine andere zu ersetzen wäre².

Die Bekanntschaft mit den ON und insbesondere den PN zeigt, daß diese Wörter in ihrer Form dem Namen des aus der Folklore bekannten Wesens Usiņ $\breve{s}$ entsprechen. Hier ist wichtig zu unterstreichen, daß die Hinweise von Plākisis auf die Revisionslisten und die Auszüge aus anderen Dokumenten eine Datierung der Namen ermöglichen. Die ältesten erhältlichen Nachrichten beziehen sich auf 1582/83, wo $\bar{U} s ̌ s$ bzw. $\bar{U} \breve{s} a$ erscheinen, und auf 1601 mit dem voll identischen Ussin (Usinšs). Das Wort ist schon vor $1606, d$. h. vor Stribinšs, bekannt und zwar auch in den anderen Gebieten Lettlands. So wird verständlich, daß seinem Eindringen in die Folklore nichts im Wege stand ${ }^{3}$.

1 Ib. 79 .

2 Über seine unkritische und freie Handhabung von $P N$ habe ich mich an anderer Stelle geäußert (cf. Biezais 1957, $26 \mathrm{~s}$ ). Im Bereich von Mutmaßungen bleibend, wünschte ich diesen Namen als $\bar{U}$ sainais 'der Schnurrbärtige' zu verstehen, d. h. als Schreib- oder Hörfehler anzusehen.

3 In diesem Abschnitt durchgeführte Quellenanalyse zeigt, daß der Gedanke von einem ,später aufgekommenen Ūsiṇšc (Šmits 1930, 204) keinen Grund hat. Hier kann man weiter einen Brief von Pastor Chr. Hentsch nennen, in welchem er im Jahre 1737 aus demselben Gebiet, Gemeinde Lazdona, schreibt, daß die Leute dort ,den baggaten Usịn (ist Georgi-Tag) “ feiern (cf. Adamovičs 1933, 488). Das Wort ,,baggaten " ist verdorbenes Lettisch und bedeutet ,,reich". 